\title{
Extraordinarily Precise Nematode Sex Ratios: Adaptive Responses to Vanishingly Rare Mating Options
}

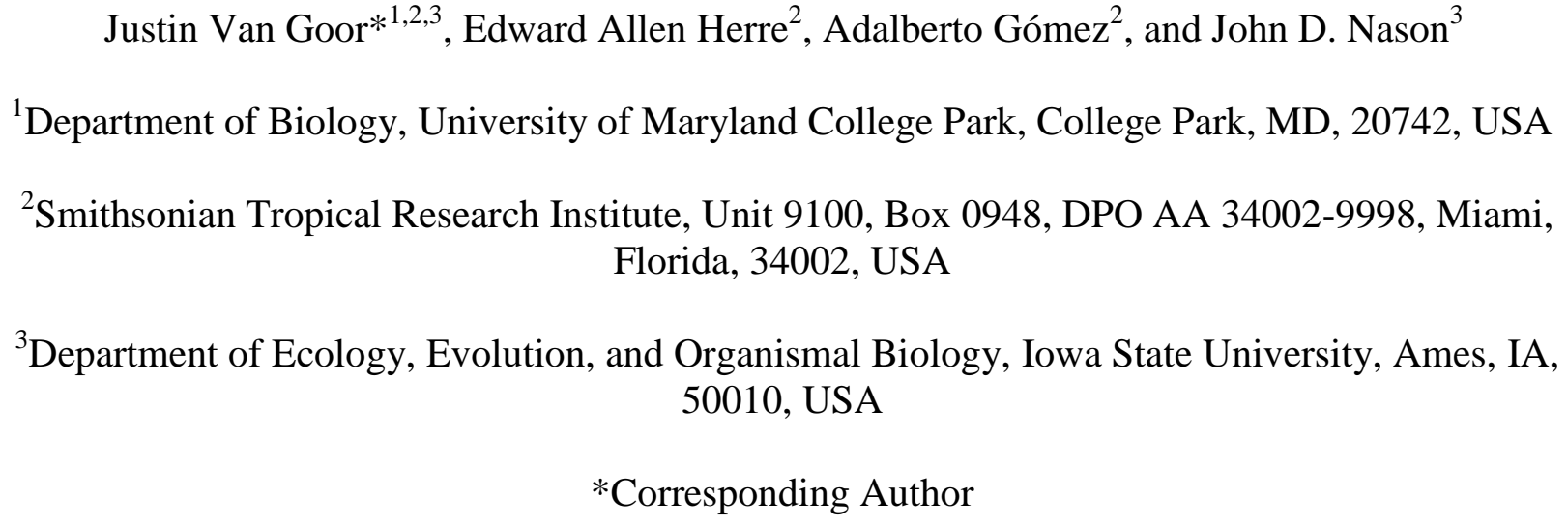

\section{$\underline{\text { Abstract }}$}

structures. Here, we compare two genera of phoretic nematodes (Parasitodiplogaster and Ficophagus spp.) associated with twelve fig-pollinating wasp species in Panama. The host wasps exhibit classic Local Mate Competition: only inseminated females disperse from natal figs, and their offspring form mating pools that consist of scores of the adult offspring contributed by one or a few foundress mothers. In contrast, in both nematode genera, only sexually undifferentiated juveniles disperse, and their mating pools routinely consist of eight or fewer adults. Across all mating pool sizes, the sex ratios observed in both nematode genera are consistently femalebiased ( 0.34 males), which is markedly less female-biased than is often observed in the host wasps ( 0.10 males). In further contrast with their hosts, variances in nematode sex ratios are also consistently precise (significantly less than binomial). The constraints associated with predictably small mating pools within highly subdivided populations appear to select for precise sex ratios that contribute both to the reproductive success of individual nematodes, and to the 
bioRxiv preprint doi: https://doi.org/10.1101/2021.05.25.445688; this version posted May 26, 2021. The copyright holder for this preprint (which

was not certified by peer review) is the author/funder, who has granted bioRxiv a license to display the preprint in perpetuity. It is made available under aCC-BY-ND 4.0 International license.

32 evolutionary persistence of nematode species. We suggest that some form of environmental sex

33 determination underlies these precise sex ratios.

34

35 Keywords: Sex allocation, sex ratio variance, environmental sex determination, Ficus, 36 Parasitodiplogaster, Ficophagus 


\section{$\underline{\text { Introduction }}$}

Sex ratio theory provides testable, quantitative predictions of population and individual adaptations expected under a wide range of selective regimes. Following Darwin (1) and Düsing (2), Fisher (3) argued that natural selection within populations of species with separate sexes should favor equal parental investment in the sexes, generally resulting in a population-wide 1:1 (0.50 males) sex ratio (4). However, Darwin knew that many organisms do not exhibit a 1:1 sex ratio; famously leaving "the problem for future generations" (5). Hamilton (6) recognized that

Fisher's argument underlying the 1:1 ratio implicitly assumed large, panmictic populations, and this assumption does not apply to many organisms. Specifically, many species are characterized by subdivided population structures, with male and female adults typically mating in isolated patches. Only mated females disperse from these patches and typically one or a few foundresses contribute offspring to subsequent mating pools (6-8).

Hamilton and others have extended sex ratio theory that was implicitly developed for panmictic populations and formalized expectations under the conditions of Local Mate

51 Competition (LMC). Under LMC, selection is expected to favor female-biased sex ratios,

52 thereby reducing competition among brothers for mates, and increasing the overall productivity

53 of the patches (6-10). Striking correspondence to specific sex ratio predictions are often observed

54 in organisms with life histories characterized by LMC (e.g., in fig pollinating wasps: 6-12). In

55 addition to exhibiting female-biased population sex ratios, individual foundresses in many 56 species appear to facultatively adjust the sex ratio of their offspring in response to cues reflecting

57 the number of other foundresses contributing broods locally to shared mating pools $(9-11,13)$.

58 Generally, foundresses that contribute relatively fewer offspring tend to produce relatively more 59 male offspring $(9-11,12-15)$. The validity of this body of evolutionary theory is firmly 

established by studies in which different experimentally imposed LMC population structures rapidly produce the corresponding predicted sex ratios (16).

In addition to successful predictions concerning population mean and facultative shifts of sex ratios, it is increasingly recognized that the body of LMC theory also makes a series of subtler predictions concerning sex ratio variance. In large, panmictic populations theoretical considerations suggest that there is little or no selection on the sex ratio of individual broods (and therefore no net selection that is expected to affect population wide variance per se). In contrast, under many scenarios with subdivided populations, selection for highly precise brood sex ratios that exhibit strikingly less than binomial variance is both expected and, in a several empirical studies, observed (11-12, 14-15, 17).

Whereas theory can predict what sex ratio means or variances are expected under different selective scenarios, sex determining mechanisms can either promote or constrain what sex ratios can actually be achieved in focal species $(7-8,13-14)$. For example, with sex determining chromosomes (e.g., XX/XY, as in most mammals, or ZW/ZZ, as in most birds and butterflies, or $\mathrm{XX} / \mathrm{X} 0$ in most nematodes), the odds that any individual offspring develops as a female or male is often roughly approximated as a coin toss. The usual result is close to a 1:1 offspring sex ratio, both within broods of individual mothers and at a population level (4). In addition, variance around the mean sex ratio is usually roughly binomial. In contrast, haplodiploid sex determination in which fertilized eggs usually develop as females and unfertilized eggs usually develop as males provides much greater variety and flexibility in both observed sex ratios and variances $(6-15,17)$.

One group of haplo-diploid organisms that have been extensively utilized to develop and test predictions from sex ratio theory are the diverse and relatively host-specific wasps 
83 (Agaonidae, Chalcidoidae) that pollinate and reproduce within the inflorescences of the roughly

84750 species of figs (Ficus, Moraceae) (18). These wasps exhibit life histories that effectively

85 define the LMC scenario (Supplement Figure S1, Table S1). Mated, pollen bearing female wasps

86 disperse to a receptive fig inflorescence or "fig" (technically a syconium) that contains scores to

87 hundreds of uniovulate flowers. Typically, one or a few foundress wasps enter the enclosed

88 structure of the receptive fig, pollinate the flowers, and lay eggs in many of them. Oviposition is

89 usually coupled with the wasp depositing a few drops of fluid that cause the oviposited flowers

90 to transform into galls, within which the wasp larvae develop (19). The offspring of successful

91 foundress wasps mature and emerge within the fig to form a local mating pool that usually

92 consist of scores of adult females and males. After mating, the next generation of mated females

93 disperse to a new fig.

The intimate association of the broods of one or a few individual foundress wasps within

95 a developing fig combines with the thousands of such individual figs on individual fig trees to

96 impose highly subdivided population structures on the wasps. Subdivided structure is most

97 extreme when only one foundress wasp contributes offspring to the mating pool within a fig

98 (single foundress brood), in which case there is complete sib-mating. Theory predicts that

101 biased sex ratios (5-10\% male) are regularly observed. Across species, the observed variance in

102 sex ratio in single foundress broods apparently reflects the frequency of single foundress broods

103 (i.e., the intensity of selection on the sex ratios in these broods, 15, Table S1). Within species,

104 mating pool sex ratios in figs that receive more foundress wasps are generally less female biased,

105 suggesting either facultative shifting of sex ratios by foundresses with shared broods or subtler 
hard-wired behaviors (e.g., "lay a set number of males and then lay females") that produce similar patterns. In wasp species with higher average foundress numbers, wasp sex ratios associated with any given number of foundresses also exhibit a less extreme female bias (10-11, Table S1). their host figs are two genera of nematodes that have independently colonized the fig-wasp mutualism. These nematodes exhibit species-specific associations with the wasps, which they exploit for dispersal and, in some cases, food. Parasitodiplogaster (Order Diplogasterida, Family Diplogastridae) are endoparasites of the wasps, whereas Ficophagus (Order Aphelenchida, Family Aphelenchoididae), previously referred to as Schistonchus in the New World, consume 116 fig tissues (20-28). Despite this dietary difference, both types of nematode are vectored by 117 dispersing female wasps. As with their host wasps, the adults of Parasitodiplogaster and 118 Ficophagus exhibit separate male and female sexes, with no evidence for self-fertility (e.g., 119 hermaphroditism or parthenogenic reproduction, 22, 26, 28-29). Unlike their host fig wasps, in which mated females disperse, only sexually 121 undifferentiated juvenile nematodes disperse. Therefore, the host wasps exhibit a strict 122 sense LMC life cycle while the nematodes do not. In fig wasps, there are usually scores of 123 individuals in a mating pool, and the sex of any one individual wasp will have relatively little 124 effect on the overall brood sex ratio. In contrast, nematodes mating pools usually consist of 4 to 12510 adults $(20,23-25,29)$, and the sex of any individual strikingly affects the overall sex ratio. In 126 fig wasps, the sex ratio expressed in brood sex ratios are primarily determined by a mated 127 foundress' tendency to fertilize eggs thereby producing daughters (by controlling the exposure of 128 eggs to sperm stored in her spermatheca $(9-11,13-14))$. In contrast, each individual nematode 
129 develops as either a female or a male only after phoretic dispersal (28). These contrasts between

130 the wasps and the nematodes motivate the following study.

Here, we present field data on mating pool sex ratios from Parasitodiplogaster and

132 Ficophagus nematode species associated with fig pollinating wasps in twelve Panamanian Ficus

133 host species. We find that nematodes exhibit female-biased sex ratios that are consistent and

134 precise (variances are consistently and dramatically lower than binomial). This precision

135 promotes reproductive and transmission success in the face of constraints imposed by

136 consistently small mating pools. We suggest that some form of post-dispersal environmental sex

137 determination (ESD) provides the mechanism underlying these observations.

\section{$\underline{\text { Study Taxa and Methods }}$}

Between December 2018 and April 2019, we sampled recently pollinated figs of

141 twelve Ficus species growing in the proximity of Barro Colorado Island, Republic of Panama.

142 The host fig species that were sampled include: F. citrifolia; F. colubrinae; F. costaricana; $F$.

$143 \quad$ dugandii; $F . \quad$ nymphaefolia; $F . \quad$ obtusifolia; $F . \quad$ perforata; $F . \quad$ pertusa; $F . \quad$ popenoei; $F$.

144 trigonata; $F$. near trigonata; and $F$. yoponensis (30). The corresponding pollinating wasp species

145 belong to the two genera: Pegoscapus and Tetrapus. They are described

146 as: Pegoscapus tonduzii; $P . \quad$ insularis/orozscoi; $P . \quad$ estherae; $\quad$ P. longiceps; $P . \quad$ piceipes; $P$.

147 hoffmeyerii; $P . \quad$ insularis; $P$. silvestris; $P . \quad$ gemellus; $P . \quad$ grandi; $P . \quad$ lopesi; and Tetrapus

148 ecuadoranus, respectively (48-50). Previous studies of Parasitodiplogaster and Ficophagus

149 (COI and 28S rDNA sequences) indicate distinct species associated with each host fig and

150 pollinator wasp species (22, 25-26, 28, 33-34). Parasitodiplogaster emerging from Pegoscapus 
151 wasps have been preserved in amber from the Dominican Republic, confirming a successful

152 evolutionary history for both the nematode and wasp host of at least 22-25 million years (22).

154 female wasps. If a wasp carrying Parasitodiplogaster or Ficophagus nematodes successfully

155 disperses to enter a receptive fig, after the foundress wasp pollinates, oviposits and dies, adult

156 nematodes will emerge from her body. The individual male and female nematodes aggregate to

157 form a mating pool, with eggs laid within the fig (Figure S1). Nematode development is

158 synchronized with wasp development so that as adult wasps begin to emerge from their galls,

159 scores to hundreds of juvenile nematodes that have molted into the infective-stage perform host-

160 seeking nictation behavior by waving back and forth. Only a small fraction of the juvenile

161 nematodes will successfully attach themselves to a female wasp and enter her body (35). Those

162 that do not contact a female pollinating wasp will not survive to reproduce.

The number of infective juvenile nematodes per individual foundress pollinator reflects

164 overall nematode density in the natal fig, and successful nematode contacts with a newly

165 emerged wasp. Nematode infection levels per wasp average 4-8 in successfully dispersed

166 foundress wasps $(20,22-25,27$, Figure 1). However, wasps infected with high numbers of

167 nematodes (> 10) are unlikely to successfully disperse to a new fig $(25,27)$, thereby limiting the

168 size of mating pools in figs $(25,27,29)$.

The number of adult nematodes comprising a mating pool is determined by the number

170 of infected foundress wasps that enter a given fig and the number of nematodes they each carry.

171 Across the Panamanian species studied here, foundress wasp numbers per fig characteristically

172 range from very low ( $\geq 95 \%$ single foundress) to relatively high (10-20\% single foundress) (23,

173 36). In fig species dominated by only one foundress wasp, the nematodes in a mating pool will 
174 typically be introduced by only a single host wasp that acquired its own infection within its natal

175 fig that also likely had only a single infected foundress. For nematode populations to persist in

176 these extreme cases, any fitness effects on the host wasp must be close to neutral, and

177 transmission from infected foundress wasps to their offspring must be essentially perfect (23-25).

178 Further, as is the case with the host wasps, we expect sib-mating will be common and the overall

179 relatedness of nematodes sharing a mating pool will be high (10). In fig species where figs are

180 typically pollinated by multiple foundresses, the constraints on nematode effects on host fitness

181 and requirements for transmission are relatively much less stringent (23-25). Moreover, in these

182 multi-foundress cases, sib-mating and the relatedness among potential mates will be lower, and

183 the number of nematodes per mating pool will often be larger (10, 23-25).

184 After determining the foundress number, we cut recently pollinated figs into quarters, 185 rinsed them with distilled water, and collected all nematodes. Based on size and morphology, we 186 differentiated adult Parasitodiplogaster from the smaller Ficophagus (26). Using light 187 microscopy, we then determined the number and sex of adults in mating pools within individual figs. Males of each species were identified based on size, the typical mating position in relation 189 to females (coiled around the female vulval region with genital papillae expressed), and with observations of genitalia $(22,34)$. In figs with a single foundress, the number of adult males and 191 females (i.e., mating pool sex ratio) associated with individual infected wasps is easy to 192 determine. Importantly, the proportion of successful foundress wasps that carry an infection can 193 also be estimated unambiguously (23-25). With multiple foundresses, it is less clear how many 194 of the wasps were infected and introduced nematodes into shared mating pools. We therefore 195 focused most analyses on single foundress figs, but also analyzed data from multi-foundress figs. 
197 (GLM) with Poisson errors and a log-link function to evaluate the relationship of host fig species 198 and foundress number per fig on mating pool size $(m)(m \sim$ host fig species + foundress 199 number). Focusing on single-foundress figs that contained nematodes, we tested the relationship 200 between fig species and mating pool size ( $m \sim$ host fig species). We also conducted two GLMs 201 with a binomial distribution and a logit-link function. The first tested the relationship between 202 sex ratio $\left(p_{m}\right.$, proportion of males) of mating pool size $m$ and fig species $\left(p_{m} \sim\right.$ host fig 203 species).The second tested sex ratio as a function of mating pool size $\left(p_{m} \sim m\right)$. All 204 GLM analyses were conducted using JMP® Pro 14 (SAS Institute Inc., Cary, NC, 1989-2019). We used simulations in $\mathrm{R}$ (37) to conduct two types of analyses of the precision of 206 observed sex ratios across the nematode mating pools in single foundress figs with different 207 numbers of total adult nematodes (mating pool size). First, we determined whether the observed 208 variance in sex ratio for a given mating pool size was significantly less than the binomial 209 variance expected with sex determining chromosomes (e.g., XX/XY, ZW/ZZ, XX/XO). The 210 expected value of the binomial variance is $p_{m}\left(1-p_{m}\right) / m$, where $m$ is the mating pool size and $p_{m}$ is 211 the overall mean sex ratio in Parasitodiplogaster or Ficophagus (0.315 and 0.353, respectively).

212 We simulated the distribution of the binomial variance in sex ratio for a given mating pool size $m$ $213=1$ to 10 , by drawing 10,000 replicates of male-female combinations from the binomial $\left(m, p_{m}\right)$ 214 with replacement, and calculated the variance in sex ratio across the $n$ samples. We conducted a 215 one-tailed test of the hypothesis that the observed variance was less than binomial variance, 216 concluding significance at the 0.05-level if the observed variance was less than or equal to the 217 value of the $500^{\text {th }}$ lowest simulated variance. $\mathrm{R}$ code for this simulation is in Supplemental 
Appendix 1. This simulation provides the expected sex ratio distributions if the sex of individual nematodes is fixed prior to dispersal from their natal fig.

Second, we determined whether the most commonly observed combination of a particular number of males and females (the dominant male-female combination) was observed more frequently than expected given sex determining chromosomes. For mating pool sizes $m=1$ to 10, we replicated 10,000 samples of observed sample size $n$ from the binomial $\left(m, p_{m}\right)$ with replacement and for each replicate determined the frequency of the dominant male-female combination that was found in the actual data. The one-tailed test of the hypothesis the observed dominant frequency is greater than expected under genetic sex determination was considered significant at the 0.05-level if the observed dominant frequency was less than or equal to the value of the $500^{\text {th }}$ highest simulated dominant frequency. $\mathrm{R}$ code for this simulation is in Supplemental Appendix 2. This provides an additional, more explicit test of whether nematode sex is determined prior to the dispersal of juvenile nematodes.

Finally, we further explored the precision of observed sex ratios for both Parasitodiplogaster and Ficophagus by determining whether the most commonly observed mating pool sex ratios were the closest possible to the observed overall mean sex ratios, given the constraints that small number impose on ratios.

\section{$\underline{\text { Results }}$}

Of 1668 figs collected from the twelve Ficus study species, 915 (55\%) showed infections by one or both nematode genera. Parasitodiplogaster nematode infections occurred in all twelve sampled Ficus species, while Ficophagus infections occurred in nine. We determined the number and sex of adult nematodes comprising mating pools for both Parasitodiplogaster and 
241 Ficophagus (523 and 165 figs respectively). The number of individual adult nematodes per

242 mating pool ranged from 1 to 45 and varied significantly with the number of foundresses per

243 fig and the host fig species: Parasitodiplogaster (GLM, $n=523, d f=12$, Chi-Square $=597.095$,

244 both $p$-values $<0.001)$ and Ficophagus (GLM, $n=165, d f=9$, Chi-Square $=102.026$, both $p$ -

245 values $<0.001)$.

Of the 593 figs with detailed information on mating pool composition, 413 were

247 pollinated by a single wasp foundress, indicating that all nematodes involved in each mating pool

248 arrived together with a single wasp. For both genera the median nematode infection per wasp

249 host was 6, with a mean of 6.214 Parasitodiplogaster adults $(n=384$ figs, standard error $=$

$0.158)$ and a mean of 6.451 Ficophagus adults $(n=93$ figs, standard error $=0.395)$ per infected

251 wasp (Figure 1). However, for both Parasitodiplogaster and Ficophagus there was significant

252 heterogeneity in the numbers of nematodes per infected wasp (GLM, $n=384, d f=11$, Chi-

253 Square $=83.630, p<0.001$, and GLM, $n=93, d f=7$, Chi-Square $=17.700, p=0.013$,

254 respectively). Mating pool sizes are summarized for single-foundress figs in Figure 1, and Table

255 S2. Data from multiple foundress figs are presented in Figure S2 and Table S4.

Across mating pool sizes, nematode sex ratios $\left(p_{m}\right)$ in single foundress figs were

257 consistently female-biased for both nematode genera, with a mean sex ratio

258 in Parasitodiplogaster of $0.315(n=384$, standard error $=0.006)$ and in Ficophagus of 0.353

$259(n=93$, standard error $=0.010)$ (Table S2A; for multi-foundress figs see Table S4). GLM

260 analyses indicate that sex ratio, $p_{m}$, did not vary significantly as a function of host fig

261 species in Parasitodiplogaster (GLM, $n=384, d f=11$, Chi-Square $=1.662, p=0.999$ )

262 or Ficophagus (GLM, $n=93, d f=7$, Chi-Square $=0.411, p=0.999$ ). Therefore, in further 
263

264

265

266

267

268

269

270

271

272

273

274

275

276

277

278

279

280

281

282

283

284

285

analyses of sex ratio, single foundress brood sex ratios were pooled across hosts. Similar results were observed in the multi-foundress dataset (both $p$-values $>0.900$ ).

Parasitodiplogaster and Ficophagus exhibited similar patterns of mating pool composition in single-foundress figs (Tables S2 and S3). In all 13 cases with only one adult nematode, that individual nematode was a female. In 26 of 38 cases of two nematode mating pools there was one male and one female, with 10 cases of two females. In 36 of 41 cases of three nematode mating pools there were two females and one male. In 41 of 58 cases of four nematode mating pools there were three females and one male, with 13 cases of two females and two males. Across all mating pool sizes with $m>1$, there was no shift in sex ratio with increasing mating pool sizes for Parasitodiplogaster (GLM, $n=372, d f=1$, Chi-square $=0.025$, $p=0.875)$ or Ficophagus (GLM, $n=91, d f=1$, Chi-square $=0.011, p=0.917)$. Further, given that roughly $95 \%$ or more of the mating pools encountered in single foundress figs exhibited 11 or fewer adult nematodes, we expect that figs exhibiting 12 or more adult nematodes likely represent cases in which more than one wasp introduced nematodes to the mating pool (Figure 1, Figure S2, Table S2). Nonetheless, we observed no difference in sex ratios in mating pools of 10 or fewer adult nematodes associated with only one infected foundress and those with mating pool sizes of 12 or more (almost certainly associated with two or more infected foundresses, in Parasitodiplogaster, $n=315, d f=1$, Chi-square $=0.080, p=0.778$; in Ficophagus, $n=56, d f$ $=1$, Chi-square $=0.710, p=0.399$ )

Importantly, in single foundress figs the observed sample sex ratios across all mating pool sizes were very precise. First, sex ratios exhibited significantly less than the binomial variance expected with sex determining chromosomes (Figure 2, Table S2). This was true for all mating pool sizes in Parasitodiplogaster. In Ficophagus, where the overall sample sizes were 
smaller, this pattern was either significant $(\mathrm{p}<0.05)$ or trending $(\mathrm{p}<0.1)$. Non-significant results tended to occur at mating pool sizes with the smallest sample sizes. Second, the dominant malefemale combinations were observed significantly more frequently than expected given sex determining chromosomes (Figure 3, Table S3). For Parasitodiplogaster, this was the case for all mating pool sizes, either assuming a mean sex ratio of $p_{m}=0.5$ or using observed nematode genus means. In Ficophagus this was the case for seven of ten mating pool sizes and marginally significant in two more. Third, the dominant male-female combinations were consistently the closest possible to the nematode genus mean observed sex ratio across all mating pool sizes in both genera (Figure 4, S3, Table S3). Results from nematode mating pools in figs with two or more foundresses do not differ significantly from those for single foundress figs (Tables S2-4).

\section{$\underline{\text { Discussion }}$}

Two nematode genera (Parasitodiplogaster and Ficophagus) have independently colonized the fig-pollinator wasp mutualism. In both lineages, there is no evidence of selffertility (either hermaphroditism or parthenogenesis, 22, 26, 28-29), and only sexually undifferentiated juveniles disperse from their natal fig. Individual nematodes do not mature sexually until after their host fig wasp successfully disperses to a receptive fig where they then form mating pools. Nematode mating pools are regularly composed of a very small number of individual males and females (median 6 total). These aspects of the nematode life cycle contrast with the classical Local Mate Competition (LMC) scenario that characterizes the host wasps (6, 9-11, Table S1). In the wasps, only mated females disperse from mating pools that occur in the natal fig. Further, the mating pools in the hosts consist of scores of adult wasps (36). Across all mating pool sizes, the sex ratios observed in both nematode genera are consistently 
female-biased (roughly one male for each 2 females, $~ 0.34$ males), which is markedly less female-biased than is often observed in the host wasps ( 0.10 males). In further contrast with their hosts (15), variances in nematode sex ratios are also consistently precise (significantly less than binomial), with the most commonly observed sex ratio (combination of males and females) presenting the closest possible sex ratio to the overall mean in both genera. We suggest that

314 constraints associated with predictably small mating pools select for the precise sex ratios, and 315 that some form of Environmental Sex Determination (ESD) provides the mechanism to achieve these precise sex ratios.

Nematode mating pools are regularly composed of a very small number of individual males and females, and, even in the median case of 6 individuals, the sex of any individual nematode has a large effect on the mating pool sex ratio $(\sim 0.17)$. Given predictably small mating pools and apparent lack of self-fertility $(22,26,28-29)$, the constraints on nematode sex ratios

321 and sexual reproduction can be most clearly appreciated in cases of the smallest mating pool 322 sizes. If sex in these nematodes were determined as it is in most mammals, birds, or other 323 nematodes, the average sex ratio is expected to be roughly $50 \%$ male, with binomial variance.

324 Under these conditions, in mating pools with 2 individual nematodes, $1 / 2$ of them would consist 325 only of males or females, and represent reproductive dead ends for both nematode individuals. 326 Similarly, in mating pools of 3 or 4 nematodes, $1 / 4$ and $1 / 8$ would represent dead ends, 327 respectively. Further, given the observed distributions of mating pool sizes, we would expect $3288.5 \%$ or more reproductive dead ends, severely threatening the persistence of many of these 329 nematode species (23-25). Instead, across Parasitodiplogaster and Ficophagus, we found only $2.7 \%$ all male or all female (apparent dead end) mating pools (Table S2). 
Beyond the scarcity of all female or all male mating pools, the observed nematode sex

332 ratios across all single foundress mating pools sizes are distinctly female biased. All else equal,

333 nematode mating pools with a female bias will be more productive due to more individual

334 females to provide local sources of eggs and juveniles (6-8). Given that higher densities of

335 juvenile nematodes in a fig contributes to the successful infection of departing mated female

336 wasps and, thereby maintain nematode populations in their hosts (23-25), it is not surprising that

337 in Parasitodiplogaster and Ficophagus the mean observed sex ratios are 0.315 and 0.353

338 respectively (Tables S2-3). If sex ratio variance were binomial, given the distribution of mating

339 pool sizes we observed, we would expect roughly $33 \%$ or more infected figs to exhibit male

340 biases in the nematode mating pools. In contrast, only $1.5 \%$ (10 total) of all mating pools

341 exhibited a male bias.

342 In both nematode genera, the dominant (most common) male-female combinations were

343 also overwhelmingly the closest possible to the overall female biased mean sex ratios, given the

344 ratios possible with the small observed numbers of individuals ( 0.34, Figures 3 and 4 , Tables

345 S2-4). This pattern in single foundress mating pools was significant in all cases except where

346 mating pool sizes were very small $(\leq 2)$ or sample sizes were unusually low. Specifically, $68 \%$

347 (26 of 38) of two-nematode mating pools exhibited one male and one female nematode (sex ratio

$348=0.50$ ), with 10 of the remaining 12 two-nematode mating pools exhibiting two female

349 nematodes. This is not consistent with one- and two-nematode mating pools representing random

350 draws from a natal pool with a sex ratio of $\sim 0.34$. Similarly, in $88 \%$ (36 of 41 ) of the three-

351 nematode mating pools there were two females and one male. In four-nematode mating pools,

352 the vast majority (97\%) of observed mating pools were either one male-three female (41 of 58) 
or two male-two female (13 of 58) combinations. Similar results were observed for the multi-

354

355

356

357

358

359

360

361

362

363

364

365

366

367

368

369

370

371

372

373

374

375

foundress dataset (Table S4).

Contrasts with the sex ratios exhibited by the Panamanian host wasps are useful for interpreting the potential constraints to the nematodes' apparently adaptive responses (differences are summarized in Table S1). We have focused our attention on nematode mating pools that resulted from only one wasp foundress introducing adult nematodes into the mating pool. This case is most closely analogous to sex ratios observed in wasp mating pools (broods) from a single foundress. Although in both the wasps and the nematodes the sex ratios are female biased, that bias is much more extreme in the wasps $(0.05-0.10$, in the wasps and $\sim 0.34$ in the nematodes, 10-11, 36). Further, the variance in sex ratios is generally much less extreme in the wasps (15, Tables S2-3). We tentatively conclude that the differences between the wasps and the nematodes in both mean and variance of sex ratio can be explained by the extreme differences in their respective mating pool sizes. Moreover, both within and across species, the wasps exhibit less female biased sex ratios in broods with larger numbers of foundresses, $(10,15,36)$. In contrast, the nematodes exhibit no evidence for more male biased mating pool sex ratios, either within or across species. The shifts in wasp sex ratios are consistent with adaptive expectations from LMC theory (9-11). Why the nematode mating pools do not analogously exhibit less female biased sex ratios when there is more than one infected wasp contributing adult nematodes, and the mating pool sizes should be sufficient to allow less female biased sex ratios, is not clear. Future experimental and comparative studies that target this question are needed.

Given obligate sexual reproduction and separate sexes, the small number of mating pools (2\%) comprised of lone females appear to be reproductive dead ends. This is especially true for nematodes associated with fig species characterized by lower numbers of foundress wasps 
376 because fewer adult nematodes are expected per fig. In the fig species with predominantly

377 single-foundress figs, the nematodes must be nearly perfect in transmission from mother to

378 daughter wasps and have negligible negative or even positive effects on wasp fitness (23-

379 25). Persistence on these hosts is especially challenged by the low numbers of adults (4-8) in

380 nematode mating pools, which presumably lower the odds of reproductive success of individual

381 nematodes, as well as threatening both ecological and evolutionary persistence of the species.

At a population level, self-fertile species potentially have up to twice the productivity and

384 Certainly hermaphroditic (41) and parthenogenetic (42-43) nematodes exist. Self-fertility ought

44). Yet, neither parthenogenesis nor hermaphroditism has been observed in either Parasitodiplogaster or Ficophagus.

The extremely stereotyped patterns of numbers of females and males within and across

391 species of both Parasitodiplogaster and Ficophagus suggest that relatively similar mechanisms

392 influence the sex of maturing nematodes in both groups. Observations in mating pool sizes of

393 one and two are not consistent with a situation in which these nematodes are drawn from an

394 initial pool of two females to each male in the natal fig. Further, the lack of sex ratio shifting in

395 mating pools with more than one infected wasp host suggest that the sex of individuals is most

396 likely determined developmentally within a host wasp just prior to emergence. We suggest that

397 individual nematodes utilize environmental cues (possibly chemical, nutritional, and/or

398 mechanical) that indicate the number and potential sex of other co-occurring nematodes, and 
influences whether individual juveniles will develop male or female. Here, it appears that this

400 pathway first induces an individual to develop as a female, with subsequent individuals

401 developing as a male. Across mating pool sizes with more than 2 individuals, a relatively

402 constant ratio of females to males (2 to 1) appears to be produced, across species and genera. which the "founder" or first individual nematode involved in a mating pool usually develops as an adult female, followed by individuals in the pool determining their sex in response to each other (8, 45-47). The phylogenetic divergence between Parasitodiplogaster, Ficophagus, and Mermithid nematodes suggest that some form of conspecific-influenced ESD mechanism evolved independently and with unique genetic/molecular pathways. Analogous density409 dependent ESD scenarios to produce adaptive sex ratios have been described for other nematodes (46, 48-49), malarial Plasmodium (50), Ctenophores (51), and in Daphnia (52), but

411 are typically associated with life histories characterized by self-fertility. We suggest that this or

412 similar ESD mechanisms allow for precise sex ratio allocation exist in numerous organisms 413 sharing similar life histories, but this prediction awaits future testing.

\section{Conclusion}

Parasitodiplogaster and Ficophagus represent distinct nematode clades that have

417 independently colonized the fig-wasps mutualism. They exploit different resource bases and

418 have persisted in Ficus communities for millions of years, despite obligate sexual reproduction

419 and routinely low numbers of female and male individuals in mating pools. Predictably low 420 mating pool sizes appear to have selected for extremely stereotyped, extraordinarily precise sex

421 ratios. The non-binomial, female-biased sex ratios are consistent with some form of 
422 environmental sex determination. However, puzzles remain. Why is there no parthenogenic or

423 hermaphroditic reproduction? Why is there no apparent sex ratio shift (less female biased)

424 observed in mating pools that have more than one source of nematodes within individual figs?

425 What are the mechanisms and evolutionary origins of sex determination in these two genera?

426 More detailed work on the mechanisms underlying these remarkably precise sex ratios and

427 constraints on even greater precision are indicated.

428

429

430

431

432

433

434

435

436

437

438

439

440

441

442

443
Acknowledgements: The authors thank D. Adams, P. Dixon, R. Giblin-Davis, J. Greeff, E. Haag, N. Kanzaki, C. Jandér, C. Machado, F. Piatscheck, E.G. Leigh., Jr., S. West, H. Kokko, and an anonymous reviewer for comments and suggestions that improved this manuscript. Funding came from the National Science Foundation (award DEB-1556853 to J. Nason, T. Heath, and E.A. Herre) and from the Smithsonian Tropical Research Institute (to E.A. Herre and J. Van Goor). The authors declare no conflicts of interest.

Data Accessibility Statement: Data and code used within this manuscript will be publically available on the Dryad and Github repositories and will be included within the supplement.

Author Contribution Statement: J. Van Goor, E. A. Herre , A. Gómez, and J. Nason all developed the conceptual design of the study, collected data, performed analyses, and contributed to the manuscript. A. Gómez collected the data on Ficophagus. J. Nason designed and ran simulations predicting binomial expectations. E.A. Herre and J. Nason provided funding. All authors approve the current draft. 
462

463

464

465

466

467

468

469

470

471

472

473

474

475

476

477

478

479

480

481

482

483

484

485

486

487

488

489

\section{$\underline{\text { References }}$}

1. Darwin, C. (1871) The Descent of Man and Selection in Relation to Sex. First Edition, John Murray, London.

2. Edwards, A. (2000) Carl Düsing (1884) on The Regulation of the Sex Ratio. Theoretical Population Biology 58: 255-257.

3. Fisher, RA. (1930) The Genetical Theory of Natural Selection. Oxford University Press, Oxford.

4. Orzack, S., Stubblefield, W., Akmaev, V., Colls, P., Munné, S., Scholl, T., Steinsaltz, D., and Zuckerman, J. (2015) The human sex ratio from conception to birth. Proceedings of the National Society America 112: 2102-2111.

5. Darwin, C. (1882) The Descent of Man and Selection in Relation to Sex. Second Edition, Fifteenth Thousand, John Murray, London.

6. Hamilton, WD. (1967) Extraordinary sex ratios. Science 156: 477-488.

7. Colwell, RK. (1981) Group selection is implicated in the evolution of female-biased sex ratios. Nature 290: 401-404.

8. Charnov, E. (1982) The Theory of Sex Allocation. Princeton University Press, Princeton.

9. Frank, S. (1985) Hierarchical selection theory and sex ratios II, on applying the theory and a test with fig wasps. Evolution 39: 949-964.

10. Herre, EA. (1985) Sex ratio adjustment in fig wasps. Science 228: 896-898.

11. Herre, EA. (1987) Optimality, plasticity, and selective regime in fig wasp sex ratios. Nature 329: 627-629.

12. Hardy, I. and Cook, J. (1995) Brood sex ratio variance, developmental mortality and virginity in a gregarious parasitoid wasp. Oecologica 103: 162-169.

13. Verhulst, E., Beukeboom, L., van de Zande, L. (2010) Maternal control of the haplodiploid sex determination in the wasp Nasonia. Science 328: 620-623.

14. Beukeboom, L. and Perrin, N. (2014) The Evolution of Sex Determination. Oxford University Press, Oxford.

15. West, S. and Herre, EA. (1998) Stabilizing selection and variance in fig wasp sex ratios. Evolution 52: 475-485.

16. Macke, E., Magalhães, S., Bach, F., Olivieri, I. (2011) Experimental evolution of sex ratio adjustment under local mate competition. Science 334: 1127-1129. 
17. Green, R., Gordh, G., Hawkins, B. (1982) Precise sex ratios in highly inbreed parasitic wasps. The American Naturalist 120: 653-665.

18. Rønsted, N., Weiblen, G., Clement, W., Zerega, N., and Savolainen, V. (2008)

Reconstructing the phylogeny of figs (Ficus, Moraceae) to reveal the history of the fig pollination mutualism. Symbiosis 45: 45-56.

19. Martinson, E., Jandér, C., Peng, Y., Chen, H., Machado, C., Arnold, A., and Herre, EA. (2014) Relative investment in egg load and poison sac in fig wasps: implications for physiological mechanisms underlying seed and wasp production. Acta Oecologica 57: 58-66.

20. Martin, G., Owen, A., and Way, J. (1973) Nematodes, figs and wasps. Journal of Nematology 5: 77-78.

21. Poinar, G. (1979) Parasitodiplogaster sycophilon gen. n, sp. n. (Diplogasteridae: Nematoda), a parasite of Elisabethiella stukenbergi Grandi (Agaonidae: Hymenoptera) in Rhodesia. Proceedings of the Koninklijke Nederlandse Akademie van Wetenschappen. 82: 375-381.

22. Poinar, G. and Herre, EA. (1991) Speciation and adaptive radiation in the fig wasp nematode, Parasitodiplogaster (Diplogastridae, Rhabditida) in Panama. Revue de Nématologie 14: 361-374.

23. Herre, EA. (1993) Population structure and the evolution of virulence in nematode parasites of fig wasps. Science 259: 1442-1445.

24. Herre, EA. (1995) Factors affecting the evolution of virulence: nematode parasites of fig wasps as a case study. Parasitology 111: S179-S191.

25. Van Goor, J., Piatscheck, F., Houston, DD., and Nason, JD. (2018) Figs, pollinators, and parasites: a longitudinal study of the effects of nematode infection on fig wasp fitness. Acta Oecologica 90: 140-150.

26. Davies, K., Bartholomaeus, F., Li, DM., Zhao, ZQ., Ye, W., and Giblin-Davis, R. (2019)

Ficophagus (Nematoda: Aphelenchoididae) from sycones of Ficus subgenus Urostigma, sections Malvanthera and Urostigma, in Eastern Australia. Nematology 1568: 1-27.

27. Gupta, S. and Borges, R. (2019) Density-dependent fitness effects stabilize parasitic hitchhiking within a mutualism. Functional Ecology 33: 2304-2315.

28. Giblin-Davis, R., Ye, W., Kanzaki, N., Williams, D., Morris, K., Thomas, WK. (2006) Stomatal ultrastructure, molecular phylogeny, and description of Parasitodiplogaster laevigata n. sp. (Nematoda: Diplogastridae), a parasite of fig wasps. Journal of Nematology 38: 137-149.

29. Gupta, S. and Borges, R. (2020) Hopping on: Conspecific traveler density within a vehicle regulates parasitic hitchhiking between ephemeral microcosms. Journal of Animal Ecology 90: 899-908. 
30. Berg, C. (1989) Classification and distribution of Ficus. Experientia 45: 605-611.

31. Wiebes, JT. (1995) Agaonidae (Hymenoptera: Chalcidoidea) and Ficus (Moraceae): fig wasps and their figs (Meso-American Pegoscapus). Proceedings of the Koninklijke Nederlandse Akademie van Wetenschappen 98: 167-183.

32. Satler, J., Herre, EA., Jandér, C., Eaton, D., Machado, C., Heath, T., and Nason, J. (2019) Inferring processes of coevolutionary diversification in a community of Panamanian strangler figs and associated pollinating wasps. Evolution 73: 2295-2311.

33. Center, B., Giblin-Davis, R., Herre, EA., and Kanzaki, N. (2010) Redescription of two Panamanian nematodes, Parasitodiplogaster citrinema Poinar \& Herre, 1991 and P. popenema Poinar \& Herre 1991 (Nematoda: Diplogastrina). Nematology 12: 89-104.

34. Kanzaki, N., Giblin-Davis, R., Ye, W., Herre, EA., and Center, B. (2014)

Parasitodiplogaster species associated with Pharmocosycea figs in Panama. Nematology 16: 607-619.

35. Lee, H., Choi, M., Lee, D., Kim, H., Hwang, H., Kim, H., Park, S., Paik, Y., Lee, J. (2012) Nictation, a dispersal behavior of the nematode Caenorhabditis elegans, is regulated by IL2 neurons. Nature Neuroscience 15: 107-112.

36. Herre, EA. (1989) Coevolution of reproductive characteristics in 12 species of New World figs and their pollinator wasps. Experientia 45: 637-647.

37. R Core Team. (2021) R: a language and environment for statistical computing. R Foundation for Statistical Computing, Vienna, Austria, URL: http://www.r-project.org/.

38. Trouvé, S., Renaud, F., Durand, P., and Jourane, J. (1996) Selfing and outcrossing in a parasitic hermaphrodite helminth (Trematoda, Echinostomatidae). Heredity 77: 1-8.

39. Denver, D., Clark, K., and Raboin, M. (2011) Reproductive mode evolution in nematodes: insights from molecular phylogenies and recently discovered species. Molecular Phylogenetics and Evolution 61: 584-592.

40. Grosmaire, M., Launay, C., Siegwald, M., Brugière, T., Estrada-Virrueta, L., Berger, D., Burny, C., Modolo, L., Blaxter, M., Meister, P., Félix, M., Gouyon, P., and Delattre, M. (2019) Males as somatic investment in a parthenogenetic nematode. Science 363: 1210-1213.

41. Yin, D. and Haag, E. (2019) The evolution of sex ratio through gene loss. Proceedings of the National Academy of Sciences USA 116: 12919-12924.

42. Cable, R. (1971) Parthenogenesis in parasitic helminths. Integrative and Comparative Biology 11: 267-272. 
43. Castagnone-Sereno, P. (2006) Genetic variability and adaptive evolution in parthenogenetic root-knot nematodes. Heredity 96: 282-289. Evolutionary Biology 9: 75.

45. Christie, J. (1929) Some observations on sex in the Mermithidae. Journal of Experimental Zoology 53: 59-76.

590

46. Tingley, G. and Anderson, R. (1986) Environmental sex determination and densitydependent population regulation in the entomogenous nematode Romanomermis culicivorax.

594 Parasitology 92: 431-449.

47. Blackmore, M. and Charnov, E. (1989) Adaptive variation in environmental sex determination in a nematode. The American Naturalist 134: 817-823. matsi (Nematoda), a parasite of the sea urchin Strongylocentrotus droebachiensis. Parasitology 600 112: 105-112.

49. Poulin, R. (1997) Population abundance and sex ratio in dioecious helminth parasites.

50. Neal, A. and Schall, J. (2014) Testing sex ratio theory with the malaria parasite Plasmodium mexicanum in natural and experimental infections. Evolution 68: 1071-1081.

607

608

609

610 production through conspecific communication. BMC Ecology 18: 12. 


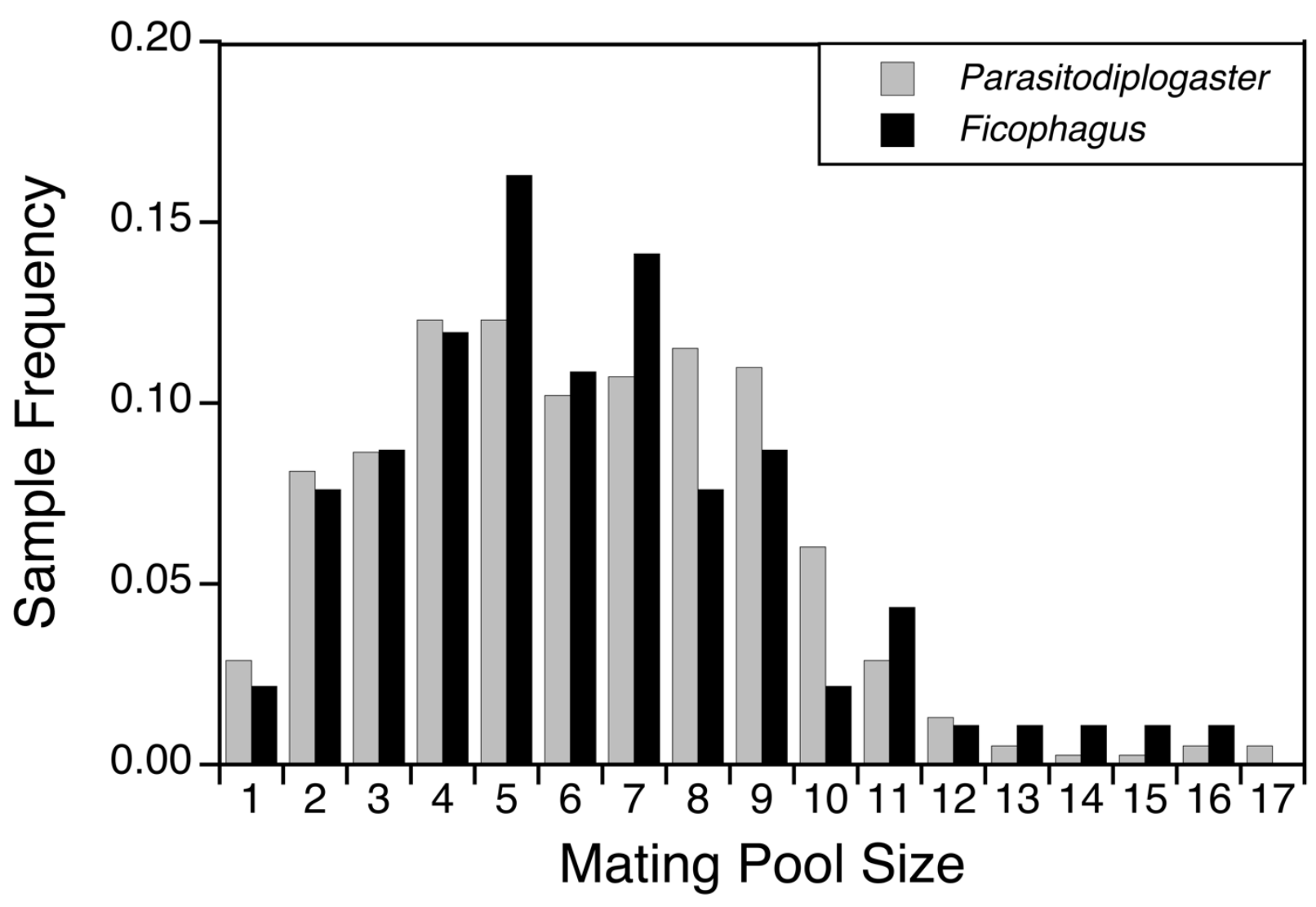

Figure 1. Relative frequencies of mating pool sizes of Parasitodiplogaster and Ficophagus nematodes found within single-foundress figs are nearly identical (384 and 93 mating pools, respectively). Data were collected and pooled from twelve Panamanian Ficus species, with a mean nematode infection load of 6.214 (Parasitodiplogaster) and 6.451 (Ficophagus) per individual wasp host. 
A

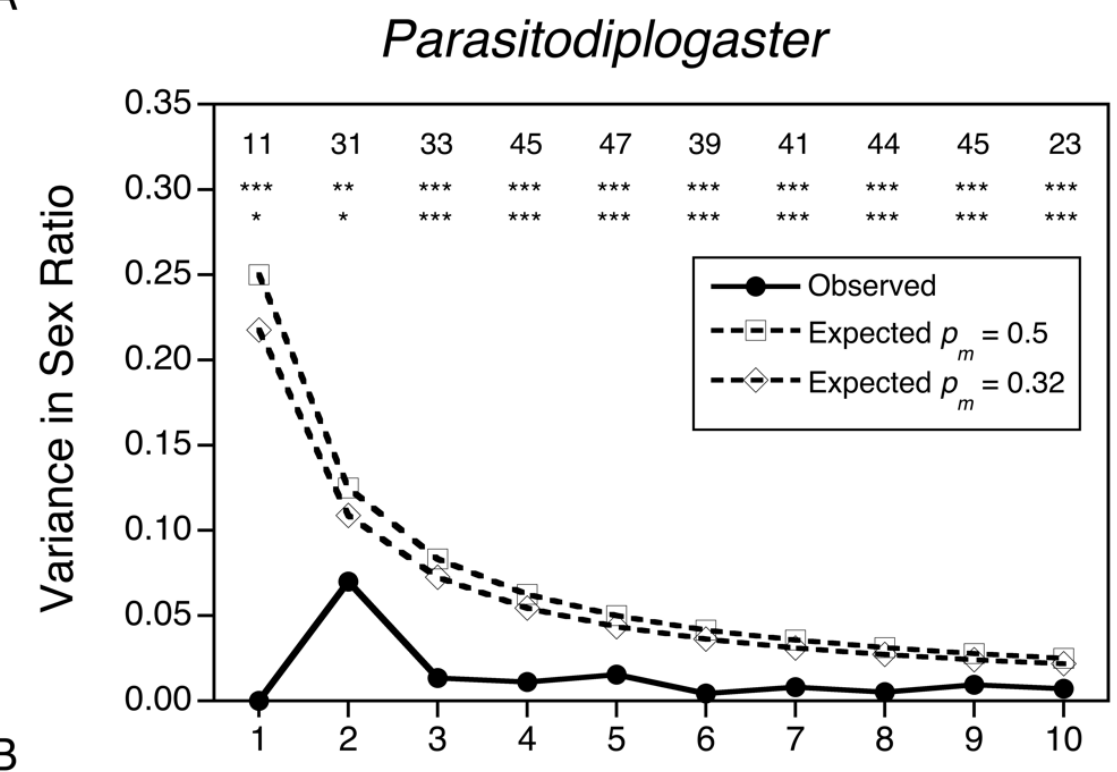

Ficophagus

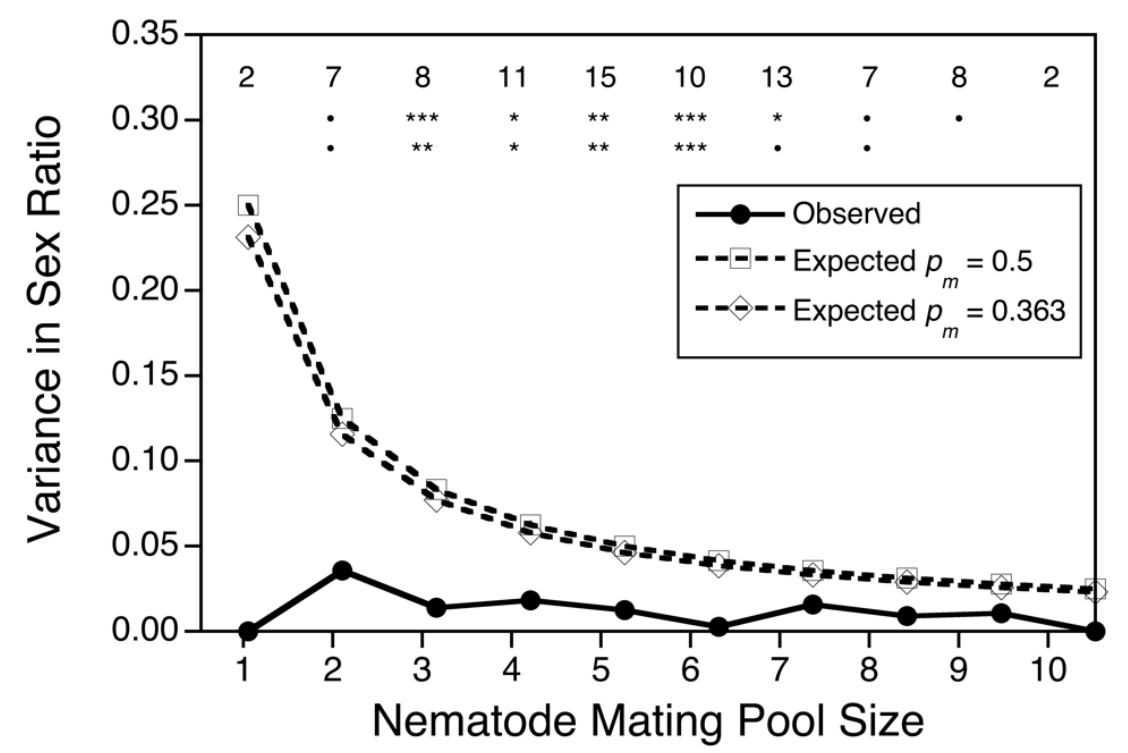

Figure 2. Comparison of the observed (solid line) and expected binomial variance (hatched lines) in sex ratio for Parasitodiplogaster (A) and Ficophagus (B) mating pools from single foundress figs. The simulated expectations assume binomial sampling given the actual number of mating pools sampled and equal sex ratios $\left(p_{m}=0.5\right)$ or average sex ratios per genus from single foundress figs (Parasitodiplogaster: $p_{m}=0.315$; Ficophagus: $p_{m}=0.353$ ). Observed sample sizes per mating pool size are indicated at the top of panels A and B, followed by significance of the difference between observed and simulated sex ratios assuming $p_{m}=0.5$ and the genus average $p_{m} . * * * * * *$ indicate $p=<0.001, p=<0.01 p=<0.05$, respectively. $\bullet$ indicates marginal significance $(p=0.1-0.05)$. The observed variance is consistently less than binomial expectations. 


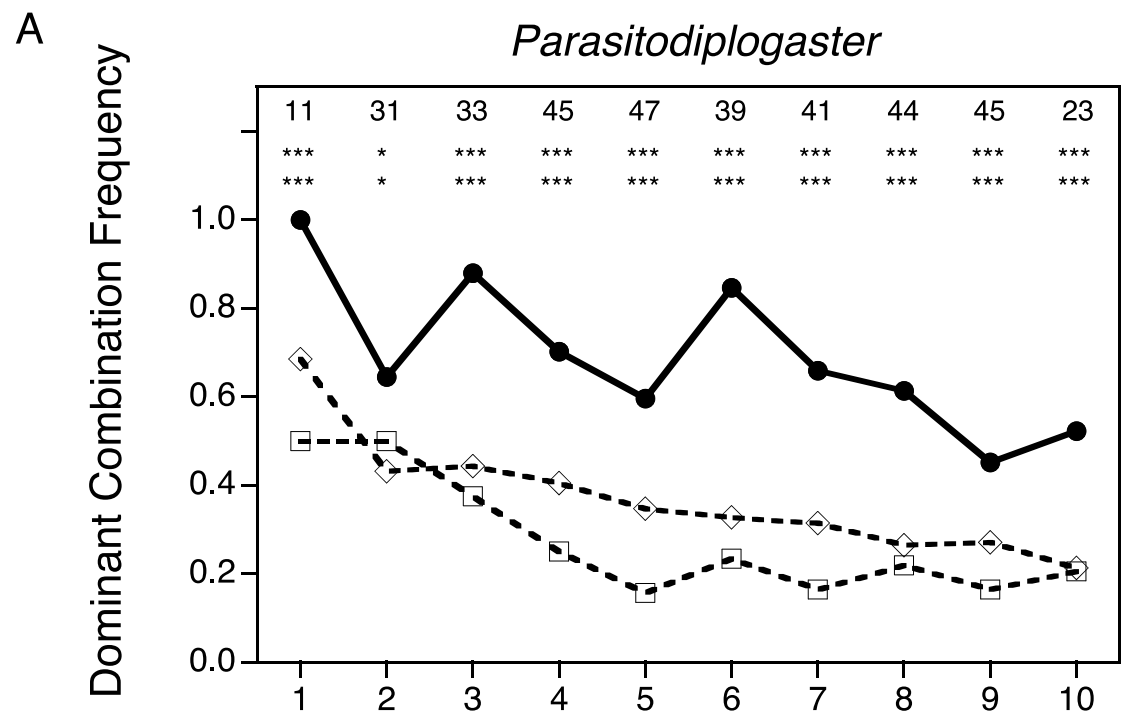

$\mathrm{B}$

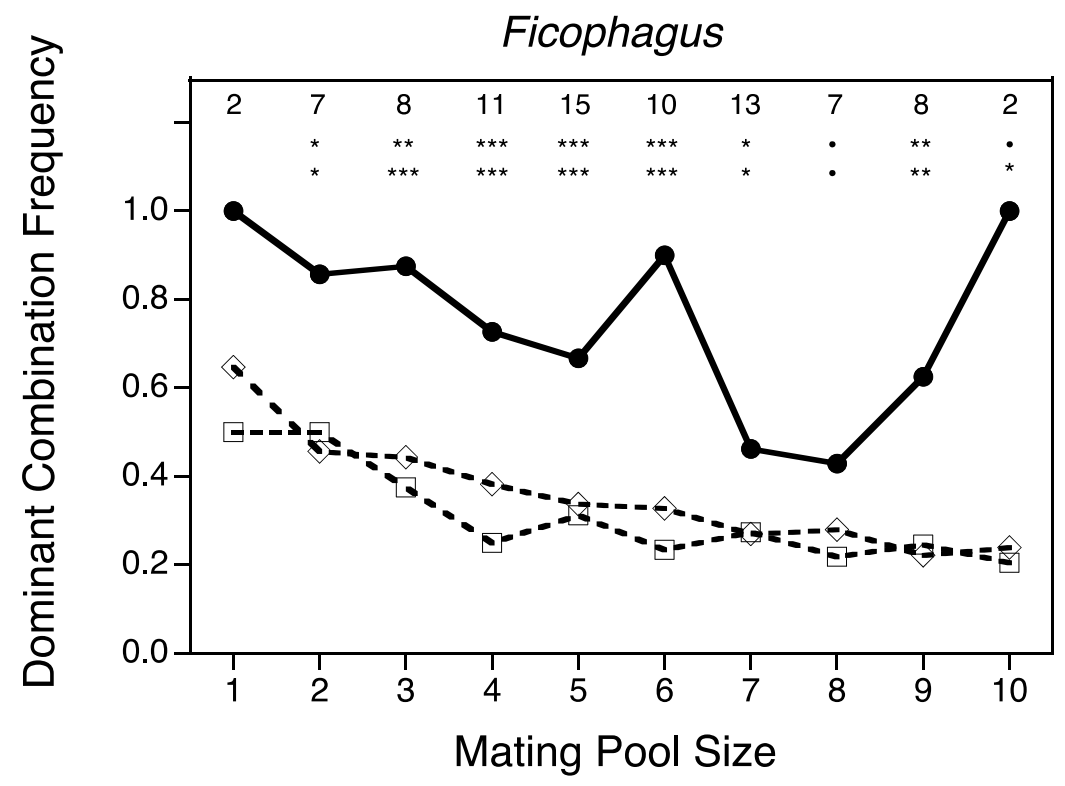

Figure 3. The observed frequency of the dominant (most common) male-female combination (solid lines, with closed circles; see Table 1) for mating pools sampled from single foundress figs

636 (Parasitodiplogaster (A) and Ficophagus (B)). This frequency is consistently greater than

637 simulated expectations assuming binomial variance given the mating pool size, number of males 638 in the dominant male-female combination, and either equal sex ratios (open squares; $p_{m}=0.5$ ) or 639 average sex ratios per genus (open diamonds; Parasitodiplogaster: $p_{m}=0.315 ;$ Ficophagus: $p_{m}=$ 640 0.353). Observed sample sizes per mating pool size are indicated at the top of each panel

641 followed by significance of the difference between observed and simulated dominant frequencies 642 for either $p_{m}=0.5$ or the genus average $p_{m}$. ***,**** indicate $p=<0.001, p=<0.01, p=<$

6430.05 , respectively. $\bullet$ indicates marginal significance $(p=0.1-0.05)$. 
644

A

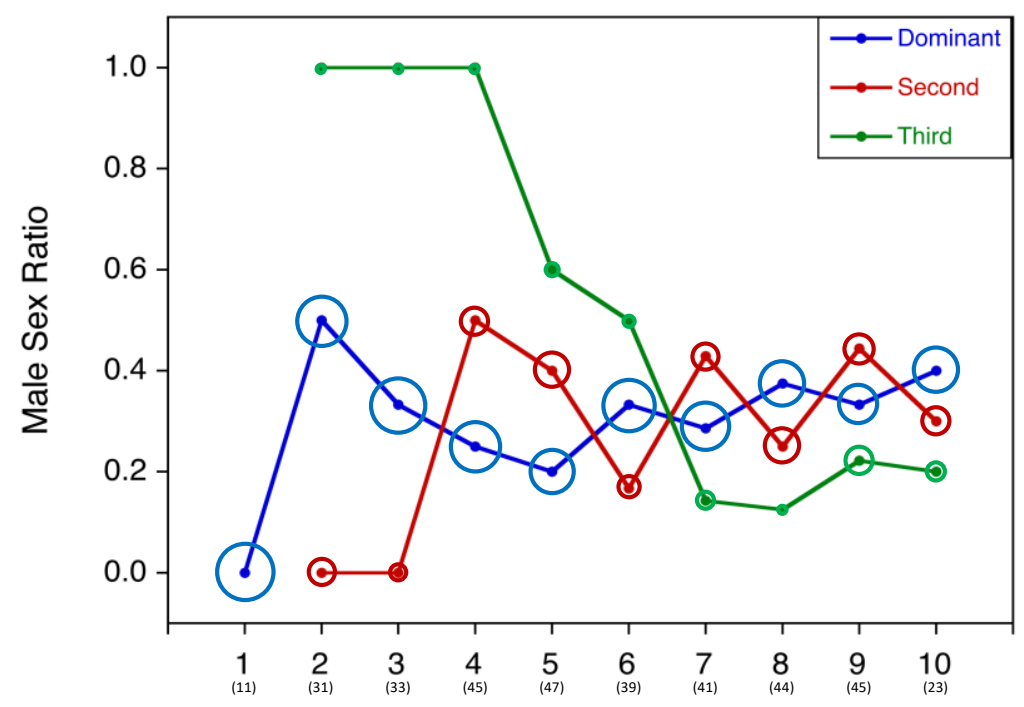

645

646

B

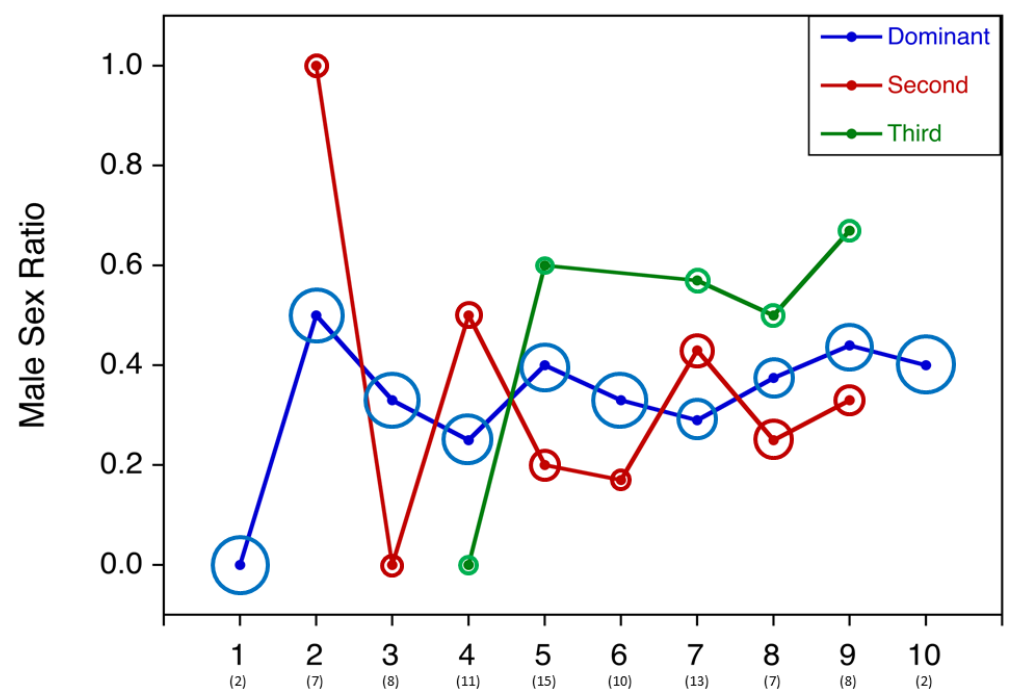

647

648

649

650

651

652

653

654

655

656

657

Nematode Mating Pool Size

Figure 4. The three most commonly observed male sex ratios (corresponding to specific combinations of males and females) for mating pools ranging from one to ten individuals in single foundress figs (Parasitodiplogaster (A) and Ficophagus (B)). The sex ratios for the dominant (most common) male-female combination are indicated by the blue datapoints. Given the numerical constraints of small numbers, these are the closest possible to the mean sex ratio for all mating pool sizes greater than one. The second (red) and third (green) most commonly observed sex ratios per mating pool are also presented. The circle surrounding each datapoint correlates to the proportion of data observed for each mating pool size. Sample sizes are given in parentheses beneath each mating pool size. 


\section{SUPPLEMENTARY MATERIALS}

660

661

662

663
Supplemental Table 1. Functional differences between pollinating fig wasp and fig nematode life histories and mating strategies.

\begin{tabular}{|c|c|c|}
\hline & Host Fig Pollinating Wasps & Fig Nematodes \\
\hline Genera/Ecology & $\begin{array}{c}\text { Pegoscapus and Tetrapus, } \\
\text { pollinators of Neotropical figs }\end{array}$ & $\begin{array}{c}\text { Parasitodiplogaster and Ficophagus, } \\
\text { phoretic on host fig wasps, former is a } \\
\text { parasite of the host wasp, latter is a parasite } \\
\text { on the host fig }\end{array}$ \\
\hline $\begin{array}{c}\text { Local Mate } \\
\text { Competition? }\end{array}$ & $\begin{array}{c}\text { Classic LMC scenario: mating and } \\
\text { competition for mates occurs in } \\
\text { natal figs }\end{array}$ & $\begin{array}{l}\text { Not a classic LMC scenario: mating and } \\
\text { competition for mates occurs only after } \\
\text { dispersal from natal fig }\end{array}$ \\
\hline Dispersal Age & $\begin{array}{l}\text { Dispersal by mated adult female } \\
\text { wasps: as successful foundresses, } \\
\text { each mated female can lay } 80 \text { or } \\
\text { more eggs in the receptive fig in } \\
\text { which her male and female } \\
\text { offspring develop }\end{array}$ & $\begin{array}{l}\text { Phoretic dispersal by sexually immature } \\
\text { juvenile nematodes, with } \sim 4-8 \text { per each } \\
\text { individual female wasp host. After the wasp } \\
\text { host oviposits and dies these nematodes } \\
\text { emerge as either males or females and mate. } \\
\text { The females then lay scores to hundreds of } \\
\text { eggs which hatch prior to the emergence of } \\
\text { host wasps. Typically, juvenile nematodes } \\
\text { greatly outnumber potential wasp hosts, and } \\
\text { many do not successfully disperse with a } \\
\text { wasp from their natal fig }\end{array}$ \\
\hline $\begin{array}{l}\text { Mating Pool Size } \\
\text { in Figs }\end{array}$ & $\begin{array}{c}\text { Large: consisting of } 80 \text { or more } \\
\text { adults that represent the offspring } \\
\text { of one or more unrelated foundress } \\
\text { wasps }\end{array}$ & $\begin{array}{c}\text { Small: consist of } 1 \text { to } 41 \text { adults (median } 6 \text { ) } \\
\text { that are dispersed as juveniles by } 1 \text { or more } \\
\text { unrelated foundress wasps }\end{array}$ \\
\hline $\begin{array}{l}\text { Population } \\
\text { Structure }\end{array}$ & $\begin{array}{l}\text { Highly subdivided: departs from } \\
\text { panmictic and varies within and } \\
\text { across species }\end{array}$ & $\begin{array}{l}\text { Highly subdivided: departs from panmictic } \\
\text { and varies within and across species. Usually } \\
\text { equally or more structured populations } \\
\text { relative to those of the host wasp }\end{array}$ \\
\hline Sex Ratio Bias & $\begin{array}{l}\text { Female bias: across species, that } \\
\text { bias is expected to be more } \\
\text { extreme in species with on average } \\
\text { fewer foundresses. Within species, } \\
\text { facultative shifts of brood sex ratio } \\
\text { away from an extreme female bias } \\
\text { are expected in response to } \\
\text { increasing numbers of foundresses }\end{array}$ & $\begin{array}{l}\text { Previously unreported. Expected sex ratio } \\
\text { less clear than in host wasps, do species with } \\
\text { higher population subdivision exhibit more } \\
\text { female biased sex ratios? Is there evidence } \\
\text { for facultative shifts? }\end{array}$ \\
\hline $\begin{array}{l}\text { Sex Determining } \\
\text { Mechanism }\end{array}$ & $\begin{array}{l}\text { Haplo-diploid sex determination: } \\
\text { mothers appear to largely control } \\
\text { the sex of individual offspring and } \\
\text { their broods as they oviposit }\end{array}$ & $\begin{array}{c}\text { Unknown: individual nematodes appear } \\
\text { capable of developing as either male or } \\
\text { female adults }\end{array}$ \\
\hline
\end{tabular}




\begin{tabular}{|c|c|c|}
\hline \multicolumn{3}{|l|}{$\begin{array}{c}\text { Observations/ } \\
\text { Results }\end{array}$} \\
\hline Sex Ratio & $\begin{array}{l}\text { Across wasp species, extreme to } \\
\text { moderate }(\sim 0.05-0.30 \text { males }) \\
\text { female bias that varies with } \\
\text { average population structure. }\end{array}$ & $\begin{array}{l}\text { Across both genera and all host species, } \\
\text { nearly constant mating pool sex ratio of } 0.34 \\
\text { males, and dominant sex ratios are generally } \\
\text { the closest possible to this value, given the } \\
\text { constraints of small number. Variance in sex } \\
\text { ratio is dramatically less than binomial. }\end{array}$ \\
\hline Sex Ratio Shift & $\begin{array}{l}\text { Within species, shift in brood (and } \\
\text { mating pool) sex ratio predictable } \\
\text { with increasing foundress number }\end{array}$ & $\begin{array}{l}\text { Within species no systematic shifting in sex } \\
\text { ratio, highly predictable, one adult is always } \\
\text { female; two adults almost always are one } \\
\text { female and one male, once mating pools } \\
\text { exceed } 2 \text { adults, always close to } 0.34 \text { males. }\end{array}$ \\
\hline $\begin{array}{l}\text { Sex Ratio } \\
\text { Flexibility }\end{array}$ & $\begin{array}{l}\text { Both across and within species, } \\
\text { mating pool sex ratios are flexible } \\
\text { and variable }\end{array}$ & $\begin{array}{l}\text { Both across and within species, mating pool } \\
\text { sex ratios are inflexible, invariant, and very } \\
\text { stereotyped }\end{array}$ \\
\hline $\begin{array}{c}\text { Sex } \\
\text { Determination } \\
\text { Control }\end{array}$ & $\begin{array}{l}\text { Maternal control of the sex } \\
\text { determination of broods and } \\
\text { resulting mating pools using } \\
\text { haplodiploidy }\end{array}$ & $\begin{array}{l}\text { Individual control of sexual expression (male } \\
\text { or female). Sex determination is almost } \\
\text { certainly some form of Environmental Sex } \\
\text { Determination. Genetic and physiological } \\
\text { mechanisms are not currently known }\end{array}$ \\
\hline
\end{tabular}




\begin{tabular}{cccccccc}
\hline $\begin{array}{c}\text { Mating } \\
\text { pool size } \\
(\boldsymbol{m})\end{array}$ & $\begin{array}{c}\text { Sample } \\
\text { size } \\
(\boldsymbol{n})\end{array}$ & $\begin{array}{c}\text { Sex } \\
\text { ratio } \\
\left(\boldsymbol{p}_{\boldsymbol{m}}\right)\end{array}$ & $\begin{array}{c}\text { Observed } \\
\text { variance in } \\
\text { sex ratio }\end{array}$ & $\begin{array}{c}\text { Expected } \\
\text { variance at } \\
\boldsymbol{p}_{\boldsymbol{m}}=\mathbf{0 . 5}\end{array}$ & $\begin{array}{c}\boldsymbol{p} \text {-value } \\
\text { given } \\
\boldsymbol{p}_{\boldsymbol{m}}=\mathbf{0 . 5}\end{array}$ & $\begin{array}{c}\text { Expected } \\
\text { variance at } \\
\boldsymbol{p}_{\boldsymbol{m}}=\mathbf{0 . 3 2 0}\end{array}$ & $\begin{array}{c}\boldsymbol{p} \text {-value } \\
\text { given } \\
\boldsymbol{p}_{\boldsymbol{m}}=\mathbf{0 . 3 2 0}\end{array}$ \\
\hline 1 & 11 & 0 & 0 & 0.250 & $* * *(-)$ & $0.218(-)$ & $*(-)$ \\
2 & 31 & 0.354 & 0.070 & 0.125 & $* *(-)$ & $0.109(-)$ & $*(-)$ \\
3 & 33 & 0.313 & 0.013 & 0.083 & $* * *(-)$ & $0.072(-)$ & $* * *(-)$ \\
4 & 47 & 0.328 & 0.021 & 0.063 & $* * *(-)$ & $0.054(-)$ & $* * *(-)$ \\
5 & 47 & 0.294 & 0.015 & 0.050 & $* * *(-)$ & $0.044(-)$ & $* * *(-)$ \\
6 & 39 & 0.325 & 0.004 & 0.042 & $* * *(-)$ & $0.036(-)$ & $* * *(-)$ \\
7 & 41 & 0.310 & 0.008 & 0.036 & $* * *(-)$ & $0.031(-)$ & $* * *(-)$ \\
8 & 44 & 0.330 & 0.005 & 0.031 & $* * *(-)$ & $0.027(-)$ & $* * *(-)$ \\
9 & 42 & 0.323 & 0.010 & 0.028 & $* * *(-)$ & $0.024(-)$ & $* * *(-)$ \\
10 & 23 & 0.357 & 0.007 & 0.025 & $* * *(-)$ & $0.022(-)$ & $* * *(-)$ \\
$>10$ & 25 & 0.343 & & & & & \\
\hline
\end{tabular}

Supplemental Table 2. The observed and expected binomial variance in nematode sex ratio in mating pools from single-foundress figs (all nematodes are introduced by a single infected wasp). Data for Parasitodiplogaster presented in Table 1A (384 sample mating pools) and for Ficophagus in Table 1B (93 sample mating pools) were collected from twelve Panamanian Ficus species. Columns indicate the mating pool size ( $m$, number of adult nematodes) found in each fig, the sample size $(n)$, the sex ratio ( $p_{m}$, mean proportion males), the observed variance in sex ratio, and then for two sex ratios ( $p_{m}=0.5$ and the observed genus mean), the expected binomial variance and the $\mathrm{p}$-value of the difference between the observed and expected sex ratios. *** indicates $p=<0.001, * *$ indicates $p=<0.01$, * indicates $p=<0.05$. (+) and (-) indicate the observed variance was greater than or less than a binomial expectation.

Table 2A. Parasitodiplogaster.

\section{Table 2B. Ficophagus.}

\begin{tabular}{cccccccc}
\hline $\begin{array}{c}\text { Mating } \\
\text { pool size } \\
(\boldsymbol{m})\end{array}$ & $\begin{array}{c}\text { Sample } \\
\text { size } \\
(\boldsymbol{n})\end{array}$ & $\begin{array}{c}\text { Sex } \\
\text { ratio } \\
\left(\boldsymbol{p}_{\boldsymbol{m}}\right)\end{array}$ & $\begin{array}{c}\text { Observed } \\
\text { variance in } \\
\text { sex ratio }\end{array}$ & $\begin{array}{c}\text { Expected } \\
\text { variance at } \\
\boldsymbol{p}_{\boldsymbol{m}}=\mathbf{0 . 5}\end{array}$ & $\begin{array}{c}\boldsymbol{p} \text {-value } \\
\text { given } \\
\boldsymbol{p}_{\boldsymbol{m}}=\mathbf{0 . 5}\end{array}$ & $\begin{array}{c}\text { Expected } \\
\text { variance at } \\
\boldsymbol{p}_{\boldsymbol{m}}=\mathbf{0 . 3 5 3}\end{array}$ & $\begin{array}{c}\boldsymbol{p} \text {-value } \\
\text { given } \\
\boldsymbol{p}_{\boldsymbol{m}}=\mathbf{0 . 3 5 3}\end{array}$ \\
\hline 1 & 2 & 0 & 0 & 0.250 & $0.505(-)$ & 0.231 & $0.540(-)$ \\
2 & 7 & 0.571 & 0.036 & 0.125 & $0.063(-)$ & 0.116 & $0.054(-)$ \\
3 & 8 & 0.291 & 0.014 & 0.083 & $* * *(-)$ & 0.077 & $* *(-)$ \\
4 & 11 & 0.273 & 0.018 & 0.063 & $*(-)$ & 0.058 & $*(-)$ \\
5 & 15 & 0.360 & 0.013 & 0.050 & $* *(-)$ & 0.046 & $* *(-)$ \\
6 & 10 & 0.317 & 0.003 & 0.042 & $* * *(-)$ & 0.039 & $* * *(-)$ \\
7 & 13 & 0.363 & 0.016 & 0.036 & $*(-)$ & 0.033 & $0.062(-)$ \\
8 & 7 & 0.340 & 0.009 & 0.031 & $0.060(-)$ & 0.029 & $0.071(-)$ \\
9 & 8 & 0.444 & 0.011 & 0.028 & $0.096(-)$ & 0.026 & $0.122(-)$ \\
10 & 2 & 0.400 & 0 & 0.025 & $0.177(-)$ & 0.023 & $0.180(-)$ \\
$>10$ & 10 & 0.349 & & & & & \\
\hline
\end{tabular}


Supplementary Table 3. Summary of the most common (dominant) male-female combinations for nematode mating pools collected from single foundress figs in twelve Panamanian Ficus species. Data for Parasitodiplogaster are presented in Table 2A (384 sample mating pools, mean sex ratio $p_{m}=0.315$ ), and for Ficophagus in Table $2 \mathrm{~B}$ (93 sample mating pools, mean sex ratio $\left.p_{m}=0.353\right)$. Columns show the mating pool size ( $m$, number of adult nematodes). For each mating pool size, the sample number of figs $(n)$, the sex ratio $\left(p_{m}\right.$, mean proportion males), the most common (dominant) male-female combination, the frequency of this combination, and the probabilities of this frequency under chromosomal sex determination. These probabilities were simulated for two assumed sex ratios ( $p_{m}=0.5$ and the observed genus mean). The observed combination frequencies were always greater $(+)$ than expected if nematodes were drawn from a source pool (e.g., natal fig) in which sex (male or female) chromosomally determined. (***,**, $*$ indicate $p=<0.001,=<0.01$, and $p=<0.05$, respectively. These results are not consistent with nematode sex ratio being determined at the time of juvenile nematode dispersal.

\section{A. Parasitodiplogaster.}

\begin{tabular}{|c|c|c|c|c|c|c|c|c|}
\hline $\begin{array}{l}\text { Mating } \\
\text { pool size } \\
(m)\end{array}$ & $\begin{array}{c}\text { Sample } \\
\text { size } \\
(n)\end{array}$ & $\begin{array}{c}\text { Sex } \\
\text { ratio } \\
\left(p_{m}\right)\end{array}$ & $\begin{array}{c}\text { Dominant } \\
\text { male-female } \\
\text { combination }\end{array}$ & $\begin{array}{c}\text { Dominant } \\
\text { combination } \\
\text { frequency }\end{array}$ & $\begin{array}{c}\text { Expected } \\
\text { frequency } \\
\text { at } p_{m}=0.5\end{array}$ & $\begin{array}{c}p \text {-value } \\
\text { given } \\
p_{m}=0.5\end{array}$ & $\begin{array}{c}\text { Expected } \\
\text { frequency at } \\
p_{m}=0.315\end{array}$ & $\begin{array}{c}p \text {-value } \\
\text { given } \\
p_{m}=0.315\end{array}$ \\
\hline 1 & 11 & 0 & $0 \hat{\bigcirc} 19$ (11 of 11$)$ & 1 & 0.500 & $* * *(+)$ & 0.685 & $* * *(+)$ \\
\hline 2 & 31 & 0.354 & $1 \widehat{\delta} 1$ ( 20 of 31$)$ & 0.645 & 0.500 & $*(+)$ & 0.432 & $*(+)$ \\
\hline 3 & 33 & 0.313 & $1 \delta 2$ ( 29 of 33$)$ & 0.879 & 0.375 & $* * *(+)$ & 0.443 & $* * *(+)$ \\
\hline 4 & 47 & 0.328 & $1 \delta 3$ ( 33 of 47$)$ & 0.702 & 0.250 & $* * *(+)$ & 0.405 & $* * *(+)$ \\
\hline 5 & 47 & 0.294 & $1 \delta^{\top} 4 \bigcirc$ (28 of 47$)$ & 0.596 & 0.156 & $* * *(+)$ & 0.347 & $* * *(+)$ \\
\hline 6 & 39 & 0.325 & $2 \widehat{\delta} 4 q$ (33 of 39) & 0.846 & 0.234 & $* * *(+)$ & 0.328 & $* * *(+)$ \\
\hline 7 & 41 & 0.310 & 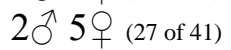 & 0.659 & 0.164 & $* * *(+)$ & 0.314 & $* * *(+)$ \\
\hline 8 & 44 & 0.330 & $3 \delta^{\lambda} 5$ (27 of 44$)$ & 0.614 & 0.219 & $* * *(+)$ & 0.264 & $* * *(+)$ \\
\hline 9 & 42 & 0.323 & $3 ठ 6$ (19 of 42) & 0.452 & 0.164 & $* * *(+)$ & 0.271 & $* * *(+)$ \\
\hline 10 & 23 & 0.357 & $4 \widehat{\jmath} 6$ (12 of 23$)$ & 0.522 & 0.205 & $* * *(+)$ & 0.214 & $* * *(+)$ \\
\hline$>10$ & 25 & 0.343 & & & & & & \\
\hline
\end{tabular}

Table 3B. Ficophagus.

\begin{tabular}{|c|c|c|c|c|c|c|c|c|}
\hline $\begin{array}{l}\text { Mating } \\
\text { pool size } \\
(m)\end{array}$ & $\begin{array}{c}\text { Sample } \\
\text { size } \\
(n)\end{array}$ & $\begin{array}{c}\text { Sex } \\
\text { ratio } \\
\left(p_{m}\right)\end{array}$ & $\begin{array}{c}\text { Dominant } \\
\text { male-female } \\
\text { combination }\end{array}$ & $\begin{array}{c}\text { Dominant } \\
\text { combination } \\
\text { frequency }\end{array}$ & $\begin{array}{c}\text { Expected } \\
\text { frequency } \\
\text { at } p_{m}=0.5\end{array}$ & $\begin{array}{c}p \text {-value } \\
\text { given } \\
p_{m}=0.5\end{array}$ & $\begin{array}{c}\text { Expected } \\
\text { frequency at } \\
p_{m}=\mathbf{0 . 3 5 3}\end{array}$ & $\begin{array}{c}p \text {-value } \\
\text { given } \\
p_{m}=0.353\end{array}$ \\
\hline 1 & 2 & 0 & $0 \delta^{\lambda} 1 \uparrow(2$ of 2$)$ & 1 & 0.500 & $0.318(+)$ & 0.647 & $0.324(+)$ \\
\hline 2 & 7 & 0.571 & $1 \delta^{\lambda} 1$ ( $(6$ of 7$)$ & 0.857 & 0.500 & $*(+)$ & 0.457 & $*(+)$ \\
\hline 3 & 8 & 0.291 & $1 \widehat{\delta} 2$ (7 of 8$)$ & 0.875 & 0.375 & $* *(+)$ & 0.443 & $* * *(+)$ \\
\hline 4 & 11 & 0.273 & $1 \widehat{\delta} 3$ (8 of 11$)$ & 0.727 & 0.250 & $* * *(+)$ & 0.382 & $* *(+)$ \\
\hline 5 & 15 & 0.360 & $2 \widehat{\jmath} 3 q$ (10 of 15$)$ & 0.667 & 0.313 & $* * *(+)$ & 0.337 & $* * *(+)$ \\
\hline 6 & 10 & 0.317 & $2 \widehat{\jmath} 4+(9$ of 10$)$ & 0.900 & 0.234 & $* * *(+)$ & 0.328 & $* * *(+)$ \\
\hline 7 & 13 & 0.363 & $3{ }^{\lambda} 4$ ( 6 of 13$)$ & 0.462 & 0.273 & $*(+)$ & 0.270 & $*(+)$ \\
\hline 8 & 7 & 0.340 & $3 \AA 5 q$ (3 of 7 ) & 0.429 & 0.219 & $0.068(+)$ & 0.279 & $0.070(+)$ \\
\hline 9 & 8 & 0.444 & $4{ }^{\lambda} 5$ ㅇ (5 of 8$)$ & 0.625 & 0.246 & $* *(+)$ & 0.222 & $* *(+)$ \\
\hline 10 & 2 & 0.400 & 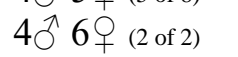 & 1 & 0.205 & $0.051(+)$ & 0.239 & $*(+)$ \\
\hline$>10$ & 10 & 0.349 & N/A & & & & & \\
\hline
\end{tabular}


707

708

709

Supplemental Table 4A. Summary data for nematode mating pools for figs containing two or more foundress. These figs were collected from twelve Panamanian Ficus species, with data for Parasitodiplogaster presented in Table 1A (141 sample mating pools, mean sex ratio $p_{m}=0.334$ ) and for Ficophagus in Table 1B (85 sample mating pools, mean sex ratio $\left.p_{m}=0.371\right)$. Columns show the mating pool size ( $m$, number of adult nematodes) found in each fig, the sample size $(n)$, the sex ratio $\left(p_{m}\right.$, mean proportion males), the dominant (most common) male-female combination, and the expected and observed variance in sex ratio (expected based on the binomial distribution with $p_{m}=0.5$ ).

\begin{tabular}{|c|c|c|c|c|c|c|}
\hline $\begin{array}{c}\text { Mating } \\
\text { pool size } \\
(m)\end{array}$ & $\begin{array}{c}\text { Sample } \\
\text { size } \\
(n) \\
\end{array}$ & $\begin{array}{c}\text { Sex } \\
\text { ratio } \\
\left(p_{m}\right)\end{array}$ & $\begin{array}{l}\text { Do } \\
\text { mal } \\
\text { com }\end{array}$ & $\begin{array}{l}\text { inant } \\
\text { female } \\
\text { ination } \\
\end{array}$ & $\begin{array}{l}\text { Expected } \\
\text { Variance }\end{array}$ & $\begin{array}{l}\text { Observed } \\
\text { Variance }\end{array}$ \\
\hline 1 & 2 & 0 & 19 & $0 O^{\prime \prime}$ (both) & 0.250 & 0 \\
\hline 2 & 15 & 0.500 & 1 우 & $1 \sigma^{\prime \prime}$ (all 15) & 0.125 & 0 \\
\hline 3 & 7 & 0.333 & 2 Q & $1 \sigma^{\prime} \quad$ (all 7) & 0.083 & 0 \\
\hline 4 & 6 & 0.292 & 39 & $1 \sigma^{\prime}(5$ of 6$)$ & 0.063 & 0.010 \\
\hline 5 & 12 & 0.283 & 4 운 & $10^{\prime \prime}(7$ of 12$)$ & 0.050 & 0.011 \\
\hline 6 & 10 & 0.283 & 4 운 & $2 \sigma^{\prime}(7$ of 10$)$ & 0.042 & 0.006 \\
\hline 7 & 12 & 0.297 & 5 ㅇ & $2 \sigma^{\prime}(9$ of 12$)$ & 0.036 & 0.005 \\
\hline 8 & 8 & 0.313 & 5 Q & $3 \sigma^{\prime}(4$ of 8$)$ & 0.031 & 0.004 \\
\hline 9 & 5 & 0.311 & 69 & $3 \sigma^{\prime}(2$ of 5$)$ & 0.028 & 0.009 \\
\hline 10 & 9 & 0.389 & 6 우 & $4 \sigma^{\prime}(8$ of 9$)$ & 0.025 & 0.001 \\
\hline$>10$ & 55 & 0.329 & & /A & $\leq 0.023$ & 0.006 \\
\hline
\end{tabular}

\section{Supplemental Table 4B.}

\begin{tabular}{|c|c|c|c|c|c|c|c|}
\hline $\begin{array}{c}\text { Mating } \\
\text { pool size } \\
(m)\end{array}$ & $\begin{array}{c}\text { Sample } \\
\text { size } \\
(n) \\
\end{array}$ & $\begin{array}{c}\text { Sex } \\
\text { ratio } \\
\left(p_{m}\right) \\
\end{array}$ & $\begin{array}{r}\text { Dor } \\
\text { male } \\
\text { comb }\end{array}$ & $\begin{array}{l}\text { nant } \\
\text { emale } \\
\text { nation }\end{array}$ & & $\begin{array}{l}\text { Expected } \\
\text { Variance }\end{array}$ & $\begin{array}{l}\text { Observed } \\
\text { Variance }\end{array}$ \\
\hline 1 & 1 & 0 & 19 & $0 \sigma^{\prime}$ & (only) & 0.250 & 0 \\
\hline 2 & 4 & 0.625 & 19 & 10 & $(3$ of 4$)$ & 0.125 & 0.063 \\
\hline 3 & 10 & 0.333 & 29 & $1 \sigma^{\prime}$ & (all 10) & 0.083 & 0 \\
\hline 4 & 15 & 0.350 & 39 & $1 \sigma^{\prime}$ & $(9$ of 15$)$ & 0.063 & 0.016 \\
\hline 5 & 10 & 0.380 & 39 & 20 & (9 of 10$)$ & 0.050 & 0.004 \\
\hline 6 & 8 & 0.333 & 49 & 20 & (all 8) & 0.042 & 0 \\
\hline 7 & 7 & 0.327 & 59 & 20 & $(5 \circ \mathrm{of} 7)$ & 0.036 & 0.005 \\
\hline 8 & 5 & 0.375 & 59 & 30 & (all 5) & 0.031 & 0 \\
\hline 9 & 2 & 0.389 & 59 & $4 \sigma^{\prime}$ & $(1$ of 2$)$ & 0.028 & 0.006 \\
\hline 10 & 3 & 0.400 & 69 & 40 & (all 3) & 0.025 & 0 \\
\hline
\end{tabular}




\section{Fig - Wasp - Nematode Lifecycles}

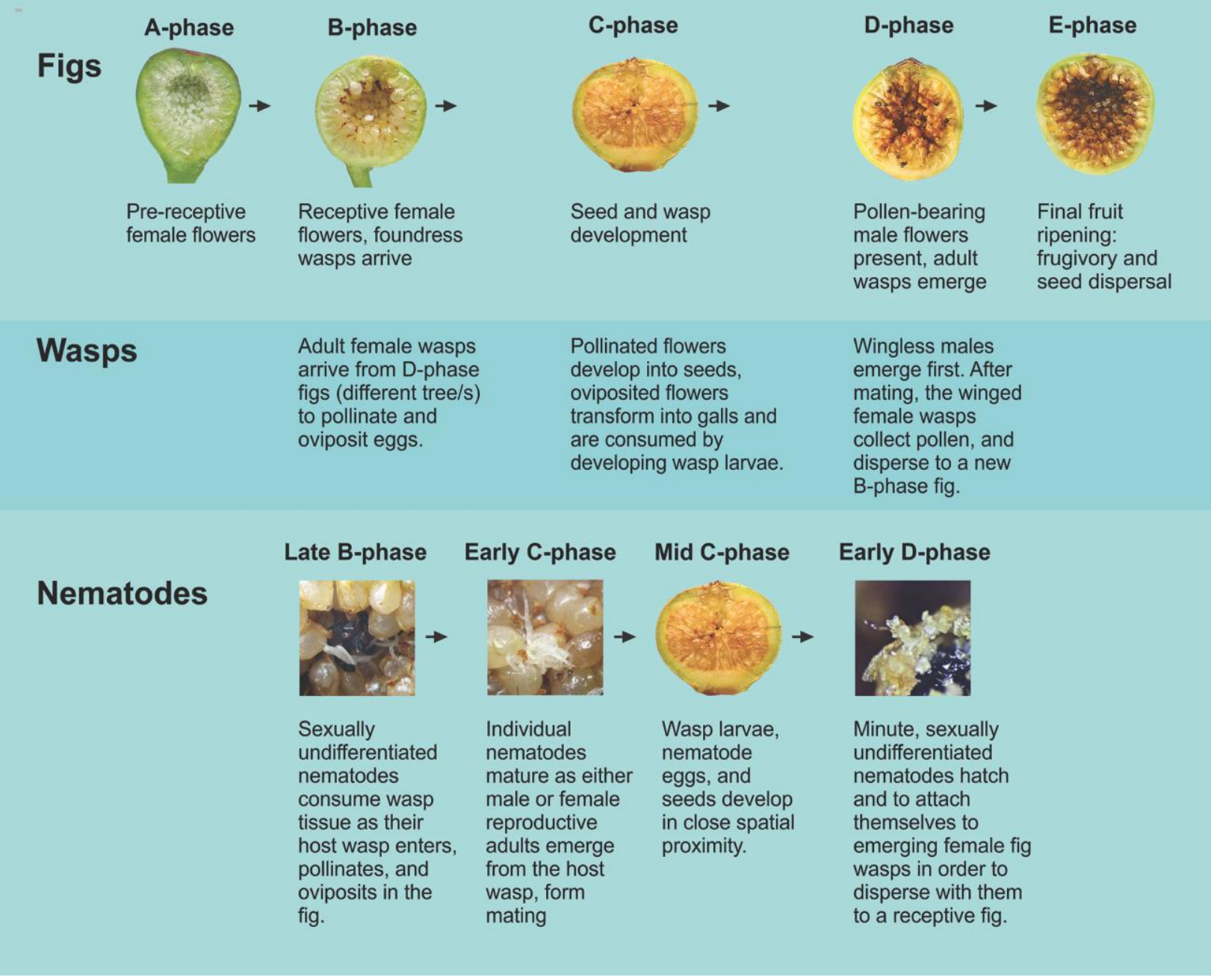

713 Supplemental Figure 1. Differences in life history characteristics between pollinating figs 714 wasps and their associated fig nematodes (Parasitodiplogaster and Ficophagus) within various 715 stages of fig development. 


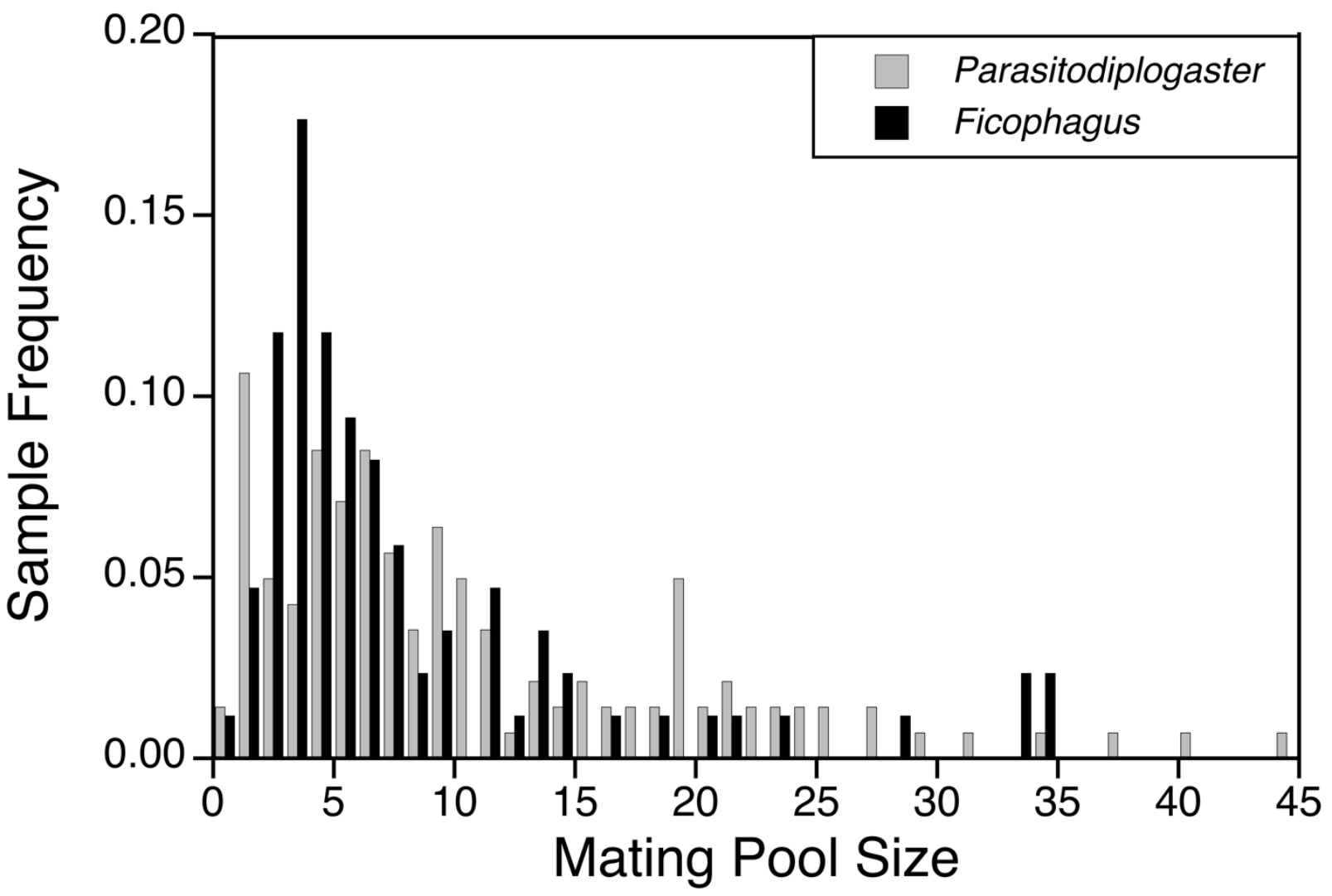

Supplemental Figure 2. Relative frequencies of Parasitodiplogaster and Ficophagus sample mating pool sizes (141 and 85 mating pools, respectively) from twelve Panamanian Ficus species exhibited in figs with two or more foundresses. The number of nematode individuals observed in these multi-foundress mating pools was greater in Parasitodiplogaster (mean $=11.199$, median $=8$, standard error $=0.743$ ) and Ficophagus $($ mean $=8.671$, median $=6$, standard error $=0.850)$ than in single-foundress mating pools (means of 6.214 and 6.451, respectively; Figure 1), suggesting that in at least some cases, more than one foundress wasps introduced a nematode infection to the shared fig. 
A.

B.
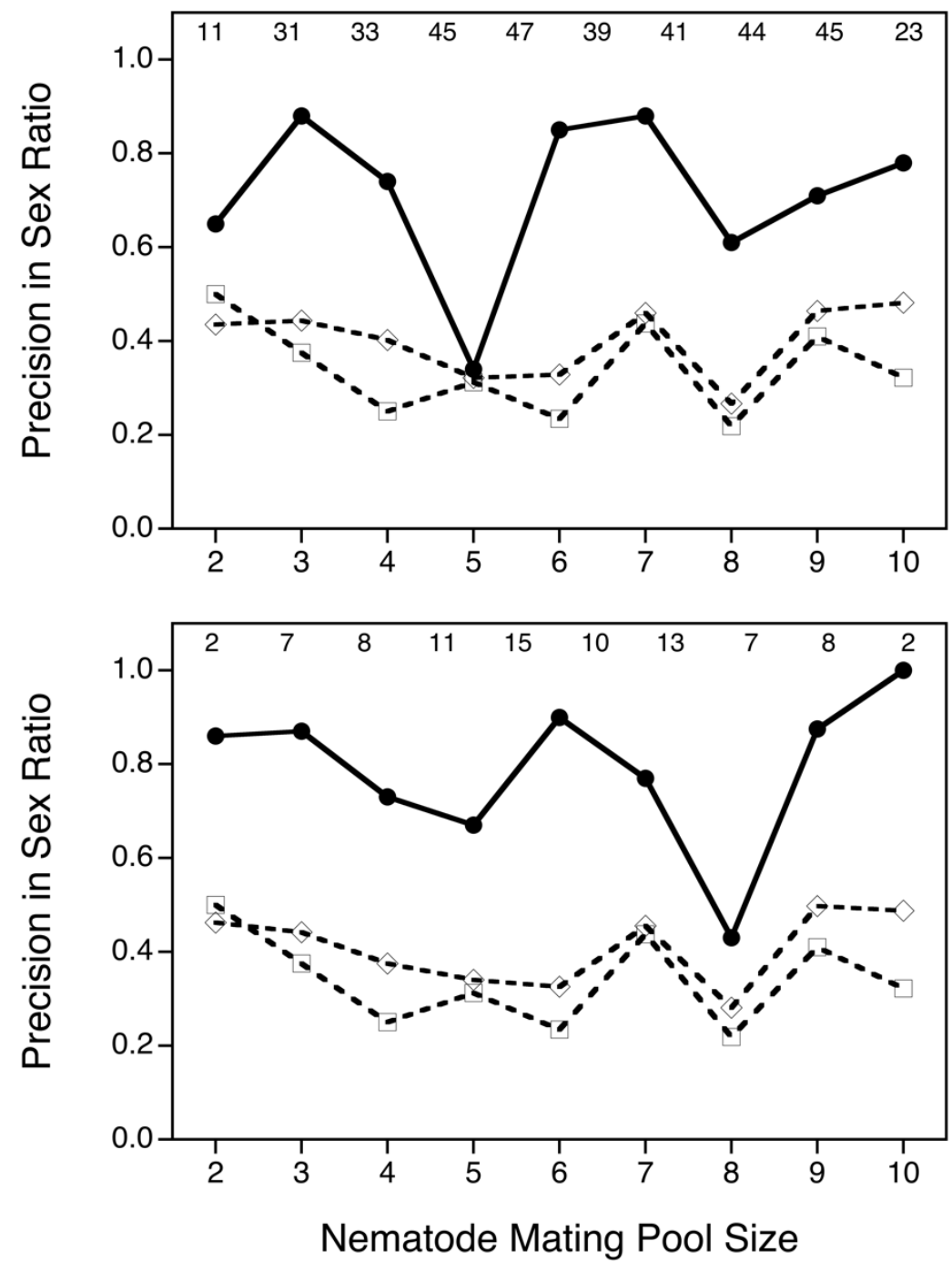

Supplementary Figure 3. The frequency with which the observed or simulated data exhibit the sex ratio closest to the overall mean (precision) in sex ratio (solid line) in single foundress mating pools for both Parasitodiplogaster (A) and Ficophagus (B). These are compared to their expected binomial frequencies (expected under chromosomal sex determination) given the actual number of mating pools sampled for both equal sex ratios $\left(p_{m}=0.5\right.$; dashed line with open squares) and the observed average sex ratios (Parasitodiplogaster: $p_{m}=0.315 ;$ Ficophagus: $p_{m}=$ 0.353; dashed line with open diamonds). Observed sex ratios (combinations of male and females) are consistently the closest possible value to the overall mean sex ratio for each genus of nematode, given the constraints imposed by small numbers (mating pool sizes). Observed sample sizes per mating pool size are indicated at the top of each panel. 


\section{Supplemental Appendix 1.}

\# Author: John Nason

\# December 1, 2020

\#\#\#\#\#\#\#\#\#\#\#\#\#\#\#\#\#\#\#\#\#\#\#\#\#\#\#\#

\#\#\# CODE OBJECTIVES \#\#\#

\# Simulation of a null distribution of Ficicola and Parasitodiplogaster

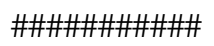

\# User settings for simulations:

768 \# Specify mating pool size, $\mathrm{m}$, sample number of mating pools, $\mathrm{N}$,

769 \# probability of male, $p$, and observed sample variance v_obs.

770 \# Values of $\mathrm{m}$ and $\mathrm{N}$ will be representative of your actual data,

771 \# while p may reflect an external null hypothesis such as a 1:1

772 \# sex ratio $(\mathrm{p}=0.5)$, or the sex ratio in your actual data.

773

$\mathrm{m}<-2 \quad$ \# Mating pool size.

$775 \quad \mathrm{~N}<-7 \quad$ \# Sample number of mating pools.

$776 \quad \mathrm{p}<-0.5 \quad$ \# User-defined sex ratio.

777 v_obs <- 0.036 \# Provide to five decimal places.

v_exp $<-p^{*}(1-p) / m$

v_exp

\#\#\#\#\#\#\#\#\#\#

\# Simulating the distribution of variance given $\mathrm{N}$ mating pools

\# of size $\mathrm{m}$ and male probability $\mathrm{p}$.

793 
nrep $<-10000$

Pmale <- matrix (rbinom(N*nrep, $m, p)$, nrow $=N) / m$

\#Pmale is a matrix with $\mathrm{N}$ rows and nrep columns.

\# Summarize the distribution of Pmale, the probability of

\# males, across all $\mathrm{N} *$ nrep simulated mating pools. For large

\# N*nrep, should be very close to binomial $(\mathrm{m}, \mathrm{p})$.

table(Pmale)

\# Calculate the simulated sample variance in Pmale for each of

\# the nrep simulated mating pools of sample size $\mathrm{N}$.

v_sim <- apply(Pmale, 2, var)

mean(v_sim)

\# Plot the distribution v_sim and it's mean value.

$\mathrm{mx}<-$ mean $\left(\mathrm{v} \_\right.$sim $) \quad$ \#Approximates $\mathrm{p} *(1-\mathrm{p}) / \mathrm{m}$ and so is independent of $\mathrm{N}$ given binomial $(\mathrm{m}, \mathrm{p})$.

hist(v_sim, xlab = paste("Variance in Pmale"), main = paste("Distribution of simulated sample variance in Pmale")) abline $(\mathrm{v}=\mathrm{mx}, \mathrm{col}=$ "blue", lwd = 2)

text $(\mathrm{x}=\mathrm{mx}, \mathrm{y}=\mathrm{nrep} / 40, \operatorname{cex}=1.25, \operatorname{pos}=4, \mathrm{col}=" \mathrm{blue} "$, paste("Mean $=$ ", $\operatorname{round}(\mathrm{mx}, 5)))$

\# The simulated variance $v_{-}$sim is a vector of length nrep. The critical

\# value, crit_val, of the one-tailed test of v_obs is less than or

\# equal to the alpha*nrep lowest value of $\mathrm{v} \_s i m_{-}$, where alpha $=0.05$ is

\# typical. If $\mathrm{v} \_$obs $\leq$crit_val, then we conclude the observed variance

\# is significantly less than expected under the binomial.

alpha $<-0.05$

crit_value $<-$ sort(v_sim, decreasing=TRUE)[length(v_sim) - alpha*nrep]

crit_value

\# The p-value (p_val) for the one-tailed test is probability of v_obs under

\# the null distribution $v_{-} \_s i m$. This is determined by the proportion of $v_{-}$sim

\# values less than or equal to v_obs.

p_val <-sum $($ round $($ v_sim, 5) $<=$ round $($ v_obs, 5)) $/$ nrep

p_val

\# Plot observed variance p_val relative to the null distribution v_sim.

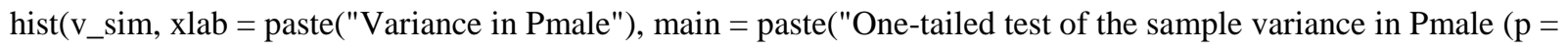

",round(p_val, 5), ")"))

if (v_obs != crit_value) \{

abline (v=crit_value, col = "blue", lwd = 2)

text(x=round(crit_value, 5), y=nrep/40, col = "blue", cex=1.25, pos=4, offset=1, paste("Critical value = ", round(crit_value, 5)))

abline $(\mathrm{v}=$ v_obs, $\mathrm{col}=$ "red", lwd $=2)$

text $(\mathrm{x}=$ round(v_obs, 5), y=nrep/80, col = "red", cex=1.25, pos=4, offset=1, paste("Observed variance = ", round(v_obs, 5)))

\} else \{

abline(v=crit_value, col = "blue", lwd = 2)

text $(\mathrm{x}=$ round(crit_value, 5), $\mathrm{y}=\mathrm{nrep} / 40, \mathrm{col}=$ "blue", cex $=1.25$, pos $=4$, offset=1, paste("Observed variance = critical value $=$ ", round $($ crit_value, 5$))$ ) 
bioRxiv preprint doi: https://doi.org/10.1101/2021.05.25.445688; this version posted May 26, 2021. The copyright holder for this preprint (which was not certified by peer review) is the author/funder, who has granted bioRxiv a license to display the preprint in perpetuity. It is made available under aCC-BY-ND 4.0 International license.

843

844 


\section{Supplemental Appendix 2.}

\section{\#\#\# CODE OBJECTIVES \#\#\#}

\# Simulation of the frequency of the dominant nematode female-male combination

\# expected under genetic sex chromosomes, which is simulated under

\# the Binomial with a user-defined sex ratio set to one-to-one or to match

\# that in the observed input data.

\# Tests the hypothesis that the observed dominant female-male combination \# frequency is significant greater than the simulated null distribution of

\# Data is read from a user-specified input Excel file in a particular format, \# as described below. Results are written to a new output Excel file, with \# frequencies and p-values modeled under GSD appended as columns to data \# from the input data file.

\# Input Excel file format (separate files by nematode genus and single- vs \# multi-foundress fruits):

\# Column headers and data:

\# A. Nematode mating pool size (m)

\# B. Sample size (n)

\# C. Overall mean sex ratio for the single- or multi-foundress data set

\# D. Sample sex ratio (pm)

\# E. Dominant male-female combination

\# F. Number of males in dominant male-female combination

\# G. Dominant male-female combination frequency

\# H. Dominant male-female combination count

\# I. Expected dominant combination frequency given $\mathrm{pm}=0.5$ (header only, no data)

\# J. p-value given pm=0.5 (header only, no data)

\# $\quad$ K. Critical value given $\mathrm{pm}=0.5$ (header only, no data)

\# L. Expected dominant combination frequency given $\mathrm{pm}=0.353$ (header only, no data)

\# $\quad$ M. p-value given $\mathrm{pm}=0.353$ (header only, no data)

\# N. Critical value given $\mathrm{pm}=0.353$ (header only, no data)

\# Rows:

\# Rows organized by mating pool size $\mathrm{m}=1$ to 10 .

\# The output file will contain the above, with results added to columns I through $\mathrm{N}$.

\# Set USER-DEFINED PARAMETERS below.

\# Runtime is dependent on sample sizes and computer. The single-foundress \# Parasitidiplogaster data set takes 27 seconds to run on a standard 2017 \# Apple MacBook. \#\#\#\#\#\#\#\#\#\#\#\#\#\#\#\#\#\#\#\#\#\#\#\#\#\#\#\#\#

\#\#\# PRELIMINARIES \#\#\# 
900

901

902

903

904

905

906

907

908

909

910

911

912

913

914

915

916

917

918

919

920

921

922

923

924

925

926

927

928

929

930

931

932

933

934

935

936

937

938

939

940

941

942

943

944

945

946

947

948

949

950

951

952

953

954

955

\# Optional: Clear all variables from the current $\mathrm{R}$ working environment.

$\operatorname{rm}($ list=ls(all=TRUE))

\# Install package to read input Excel data file into a dataframe.

\#install.packages("readxl")

library(readxl)

\# Install package to write final output dataframe to Excel data file.

\#install.packages("writexl")

library(writexl)

\#\#\#\#\#\#\#\#\#\#\#\#\#\#\#\#\#\#\#\#\#\#\#\#\#\#\#\#\#\#\#

\#\#\# USER-DEFINED PARAMETERS \#\#\#

\# Set path to directory where the input data file is located.

\# For Parasitodiplogaster:

cwd <- " /Dropbox/Manuscripts/Van Goor, Justin/Sex Ratio Paper/Figures 2020-04-19/Figure

2/Data/Parasitodiplogaster/"

\# For Ficophagus:

\#cwd <- " /Dropbox/Manuscripts/Van Goor, Justin/Sex Ratio Paper/Figures 2020-04-19/Figure

2/Data/Ficophagus/"

\# Set input Excel file name.

input.file.name <- "Parasitodiplogaster_Dom_Freq_Data.xlsx"

\#input.file.name <- "Ficophagus_Dom_Freq_Data.xlsx"

\# Set output file name.

output.file.name <- "Parasitodiplogaster_Dom_Freq_Test_OutXXX.xlsx"

\#output.file.name <- "Ficophagus_Dom_Freq_Test_Out.xlsx"

\# Number of simulated replicates.

n.reps <- 10000

\# Critical value of one-tailed test of the hypothesis that the dominant male-female

\# combination is higher than expected under GSD.

alpha $<-0.05$

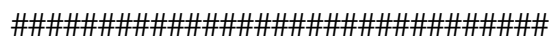

\#\#\# CODE \#\#\#

\# Start clock

ptm $<$ - proc.time ()

\# Set output file path

output.file.path <- paste(cwd, output.file.name, sep="")

output.file.path

\# Import input data file into a data frame.

\# Get the path to the input Excel data file.

input.file.path <- paste(cwd, input.file.name, sep="")

input.file.path 
\# Read input data from Excel file.

df <-read_excel(input.file.path, skip $=1$, col_names = TRUE)

\#sapply(df, mode)

View(df)

ed_mp6 <- df[-c(6,)]

View(ed_mp6)

\# Convert df to matrix.

df.mat $<-$ as.matrix $(\mathrm{df})$

\# Get mating pool sizes from df.mat and store in a vector.

mating.pool.size.vec <- as.integer(df.mat[,1])

\# Get mean observed sex ratio (is constant across rows of df.mat column 3).

p.bar <- as.numeric (df.mat $[1,3])$

p.gsd $<-c(0.5$, p.bar $)$

\#\#\#\#\#\#\#\#\#\#

for(g in p.gsd $)\{$

\# Create a vector to store simulated values of the expected frequency of

\# the dominant male-female combination.

f.dom.exp.vec <- vector()

crit.value.high.vec <- vector()

p.val.vec <- vector()

for(i in mating.pool.size.vec) \{

\# Read in required input data from dataframe df

\# Mating pool size.

$\mathrm{m}<-$ as.integer(df.mat $[\mathrm{i}, 1])$

\# Sample number of mating pools.

$\mathrm{N}<$ - as.integer(df.mat [i,2])

\# Mean sex ratio over all sample mating pools.

p.bar <- as.numeric(df.mat[i,3])

\# Sex ratio at current mating pool size.

$\mathrm{p}<-$ as.numeric (df.mat $[\mathrm{i}, 4]$ )

\# Number of males in dominant male-female combination.

n.males <- as.integer(df.mat[i,6])

\# Observed frequency of dominant male female combination.

f.dom <- as.numeric(df.mat [i,7])

\# Number of times the dominant female-male combination was observed

\# across $\mathrm{N}$ sample mating pools.

n.dom <- as.numeric (df.mat $[i, 8])$

\#print(n.dom)

\#\#\#\#\#\#\#\#\#

\# Expected frequency of the observed dominant female-male combination \# under GSD assuming a binomial with mating pool size m, n_males_dom, \# and sex ratio p.gsd. For each $\mathrm{m}$, store exp.freq in a vector. exp.freq <- $\operatorname{dim}(\operatorname{combn}(\mathrm{m}, \mathrm{n} . \mathrm{males}))[2]^{*}\left(\mathrm{~g}^{\wedge} \text { n.males }\right)^{*}\left((1-\mathrm{g})^{\wedge}(\mathrm{m}-\mathrm{n} \cdot \mathrm{males})\right)$ f.dom.exp.vec <- c(f.dom.exp.vec, exp.freq) 
\# Number of times the dominant female-male combination is expected \# across $\mathrm{N}$ sample mating pools under GSD.

\section{\#\#\#\#\#\#\#\#\#\#}

\# Simulate counts of the dominant nematode female-male combination \# expected under GSD. Test the observed count of the dominant female\# male combination relative to the simulated null distribution.

\# Simulate $\mathrm{N}$ mating pools (given $\mathrm{m}$ and $\mathrm{p}$ ) n.reps times under the \# binomial assuming GSD.

Pmale.mat <- matrix $($ rbinom $(\mathrm{N} *$ n.reps, $m$, p.gsd $)$, nrow=N) $/ \mathrm{m}$

\#Pmale.mat is a matrix with $\mathrm{N}$ rows and n.reps columns.

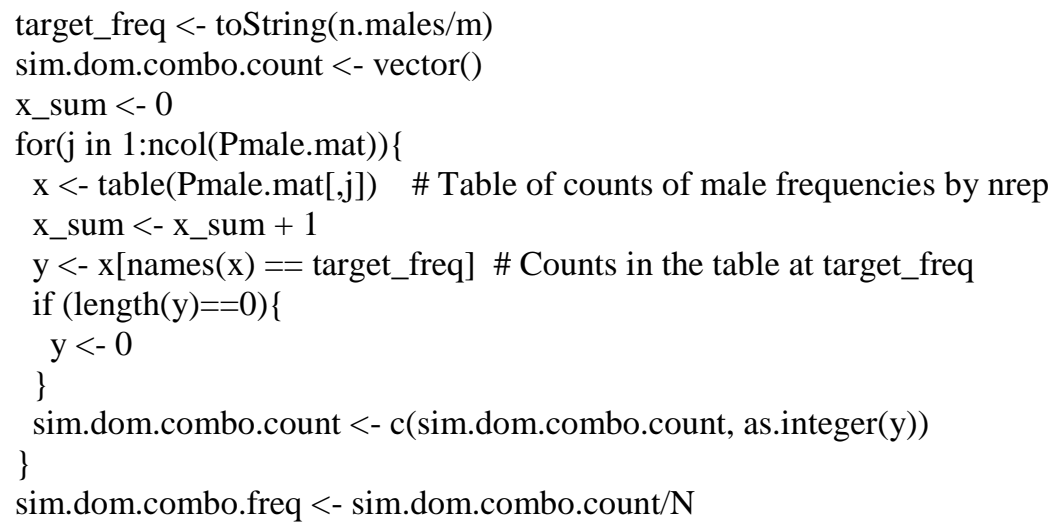

\# The simulated female-male combos sim.dom.combo.count is a vector of length \# n.reps. The critical values of the two-tailed test of n.dom are the alpha*n.reps \# lowest and (1-alpha)*n.reps highest values sim.dom.combo.count, \# where alpha $=0.025$ is typical. If obs_dom_combo_count lies beyond these two \# critical values then we conclude obs_dom_combo_count is significantly \# different than expected under the GSD binomial model.

\#crit.value.low <- sort(sim.dom.combo.freq)[length(sim.dom.combo.freq) - (1-alpha)*n.reps] crit.value.high <- sort(sim.dom.combo.freq)[length(sim.dom.combo.freq) - alpha*n.reps] crit.value.high.vec <- c(crit.value.high.vec, crit.value.high)

\# The p-value (p_val) for the two-tailed test is the probability of \# obs_dom_combo_count under the null distribution sim_dom_combo_count. \# This is determined by the lower of the proportion of sim_dom_combo_count \# values less than or equal to crit_value_low or greater than or equal \# to crit_value_high. p.val.high $<-$ sum $($ sim.dom.combo.freq $>=$ f.dom $) /$ n.reps p.val.vec <- c(p.val.vec, p.val.high)

1067 \} 
bioRxiv preprint doi: https://doi.org/10.1101/2021.05.25.445688; this version posted May 26, 2021. The copyright holder for this preprint (which

was not certified by peer review) is the author/funder, who has granted bioRxiv a license to display the preprint in perpetuity. It is made available under ACC-BY-ND 4.0 International license.

1068

1069

1070

1071

1072

1073

1074

1075

1076

1077

1078

1079

1080

1081

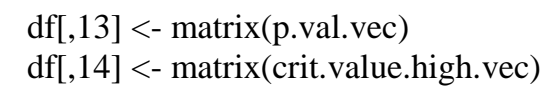

\# Write results to new Excel file.

write_xlsx (df, output.file.path, col_names = TRUE, format_headers = TRUE)

\# Elapsed time.

proc.time ()$-$ ptm 